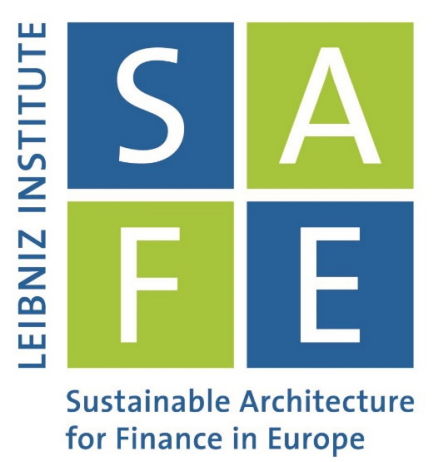

Sabine Bernard | Benjamin Loos | Martin Weber

\title{
The Disposition Effect in Boom and Bust Markets
}

SAFE Working Paper No. 305

\section{Leibniz Institute for Financial Research SAFE}

Sustainable Architecture for Finance in Europe 


\title{
The Disposition Effect in Boom and Bust Markets
}

\author{
Sabine Bernard*, Benjamin Loos $^{\dagger}$, and Martin Weber
}

\begin{abstract}
The disposition effect is implicitly assumed to be constant over time. However, drivers of the disposition effect (preferences and beliefs) are rather countercyclical. We use individual investor trading data covering several boom and bust periods (2001-2015). We show that the disposition effect is countercyclical, i.e. is higher in bust than in boom periods. Our findings are driven by individuals being $25 \%$ more likely to realize gains in bust than in boom periods. These changes in investors' selling behavior can be linked to changes in investors' risk aversion and in their beliefs across financial market cycles.
\end{abstract}

Keywords: Disposition Effect, Financial Market Cycles, Household Finance, Retail Investor

JEL Classification: D14, G11, G28

* Sabine Bernard (bernard@safe-frankfurt.de) is affiliated with the Graduate School of Economic and Social Sciences (GESS) the University of Mannheim (B6, 30-32, 68159 Mannheim, Germany) and the Leibniz Institute for Financial Research SAFE (Theodor-W.-Adorno-Platz 3, 60323, Frankfurt am Main, Germany).

† Benjamin Loos (benjamin.loos@tum.de) is affiliated with the Technical University of Munich (Arcisstr. 21, 80290 Munich, Germany).

‡ Martin Weber (weber@bank.bwl.uni-mannheim.de) is affiliated with the University of Mannheim (L9, 1-2, 68131 Mannheim, Germany).

We thank seminar participants at the University of Mannheim, Ludwig Maximilian University of Munich, and Goethe University Frankfurt as well as participants at the Annual Meeting of the American Finance Association 2020, the Annual Meeting of the European Economic Association 2020, the SAFE Household Finance Workshop 2019, the Annual Meeting of the German Finance Association 2019, and the Boulder Summer Conference on Consumer Financial Decision Making 2019 for helpful suggestions. We gratefully acknowledge research support from the Leibniz Institute for Financial Research SAFE. 


\section{Introduction}

The disposition effect, namely investors' tendency to sell winners more frequently than losers (Shefrin and Statman, 1985), is one of the most explored behaviors in finance. A large number of studies document the presence of the disposition effect among different investor types, in various asset classes, and across geographical regions. ${ }^{1}$

While there exists strong empirical evidence for the disposition effect, authors investigating the disposition effect use data that mostly cover boom periods and implicitly assume that the disposition effect is constant over time. ${ }^{2}$ Yet, recent research on the proposed drivers of the disposition effect, preferences and beliefs, show that these drivers are changing with boom and bust cycles. Experimental literature exploring changes in investors' preferences shows that investors are more risk averse in bust periods (Cohn, Engelmann, Fehr, and Maréchal, 2015) or in negative emotional states such as anxiety (Loewenstein, Weber, Hsee, and Welch, 2001; Kuhnen and Knutson, 2011). Further, Guiso, Sapienza, and Zingales (2018) find empirical evidence that following the 2008 crisis, both qualitative and quantitative measures of risk aversion increased substantially. Likewise, investors' beliefs vary over time. Malmendier and Nagel (2011) find that investors who experienced low stock market returns throughout their lives hold more pessimistic beliefs about future stock market returns and more recent return experiences have stronger effects. In particular, recent events such as financial crises can trigger changes in investors' return expectations (Weber, Weber, and Nosic, 2013). The notion that macroeconomic conditions impact investors' beliefs is also found using survey data (Vissing-Jorgensen, 2003; Dominitz and Manski, 2010). Greenwood and Shleifer (2014) as well as Amromin and Sharpe (2014) find investors' expectations to be extrapolative and influenced by economic conditions, i.e., to be positively correlated with past stock market returns.

The aim of this paper is to investigate whether the disposition effect is constant over time or if the disposition effect moves with stock market cycles (i.e., boom and bust periods).

\footnotetext{
${ }^{1}$ For related literature see Appendix A Panel 1.

${ }^{2}$ For papers and time periods see Appendix A Panel 2.
} 
We analyze a large German retail investor data set containing private investor trading and portfolio data from 2001 to 2015 - which is almost three times the length of other datasets (see column Sample Period in Appendix A Panel 2). We show that the disposition effect is not constant over time. In particular, we demonstrate that the disposition effect moves countercyclical with the stock market (Figure 1). Here, the disposition effect and the stock market return are negatively correlated with a Pearson's correlation coefficient of -0.76 .

\section{[Insert Figure 1 here]}

In other words, the disposition effect is highest in periods when the financial market is down and lowest in periods when the financial market is up. In order to assess whether a market is in a down or up state, we use a bear market indicator that equals one if the excess (of risk-free rate) cumulative $\mathrm{CDAX}^{3}$ return in the past 24 months is negative and zero otherwise (Daniel and Moskowitz, 2016). ${ }^{4}$ The disposition effect is the difference in the propensity to sell a stock at a gain (PGR) and the propensity to sell a stock at a loss (PLR). An asset trades at a gain whenever the value-weighted average purchase price is strictly smaller than the asset's current market price. In boom periods the disposition effect is $5.42 \%$ (PGR$P L R=18.9-13.48$ ) and in bust periods the disposition effect is 10.6\% (PGR-PLR $=23.9-13.3)$. In absolute terms, the disposition effect is 5.18 percentage points higher in bust than in boom periods. This finding highly statistically significant and robust across several model specification. In our most conservative estimation approach, the disposition effect in bust periods is still 4.83 percentage points higher than the disposition effect in bust periods. This difference in the disposition effect between boom and bust cycles is mainly driven by investors' increased propensity to realize gains in bust periods (18.9 vs. 23.9). Investors are in relative terms, more than $25 \%$ more likely to realize a winner asset in bust than in boom periods. The realization of losses does not change significantly across boom and bust markets (13.48 vs. 13.3).

\footnotetext{
${ }^{3}$ The CDAX is a German stock market index that comprises all stocks traded on the Frankfurt Stock Exchange that are listed in the Prime or General Standard market segment.

${ }^{4}$ In robustness test, we further employ four alternative boom-bust classification and vary the market index. Results stay the same.
} 
Why do we observe these changes in investors' selling behavior across stock market cycles? As outlined above, researcher show that the proposed drivers of the disposition effect are affected by market cycles. To shed light on the channel (i.e. preferences and beliefs) that drives our results, we analyze the impact of the magnitude and the timing of gain and loss realizations in boom and bust markets.

Throughout this study, investors have prospect theory (PT) preferences. If investors are more risk-averse in bust than in boom periods (e.g. Cohn et al., 2015), then investors' preference parametrization differs in boom and bust periods. More precisely, bust investors have a lower coefficient of risk aversion (i.e. alpha) than boom investors. This difference in preference parameter values affects investors' decision problem, i.e. selling versus holding on to a risky asset. Prospect theory predicts that the propensity to sell a stock, i.e. PGR and PLR, declines as its price moves away from the reference point (Kaustia, 2010). Hence, the function of the value of selling an asset minus the value of holding on to an asset decreases with a gain's/loss's magnitude. If investors become more risk averse in bust periods, this function will shift upwards predicting a higher PGR and PLR in bust than in boom periods. This will be show more explicitly in Figure 2 of chapter 5.1. Moreover, a change in the coefficient of risk aversion will have a stronger effect on PGR than on PLR since changes in the coefficient of risk aversion will affect investor's decision problem in the gain domain through the value of selling and the value of holding on to the asset, whereas, in the loss domain, a change in alpha only affects the value of holding on to the risky asset. In section 5.1, we will show that under PT preferences (Tversky and Kahneman, 1992) the coefficient of risk aversion only affects the gain and not the loss domain. ${ }^{5}$

Analyzing investors' selling behavior over a range of return intervals (-30\% to $+30 \%)$ rather than just focusing on positive versus negative returns, we find that investors are always more likely to sell an asset in a bust than in a boom period - irrespective of the gain's/loss's magnitude. This is in line with theory predicting an upward shift of investors' decision problem function if alpha decreases. It further shows, that our main finding is not driven by some extreme return realizations but a stable result. Examining PGR and PLR over a range of return

\footnotetext{
${ }^{5}$ Theoretical predictions are explained in more detail in section 5.1.
} 
intervals, we further find differences in gain (loss) realization to be strong (neglectable) across boom and bust markets. Again, this is in line with theory predicting changes in the coefficient of risk aversion do primarily affect gain and not loss realizations.

To investigate the effect of changes in beliefs in market cycles, we look at investors' timing ${ }^{6}$ of sales within and across boom and bust cycles. There exists evidence that investors' beliefs are positively correlated with past stock market returns which makes investors overly optimistic (pessimistic) in boom (bust) periods (e.g. Greenwood and Shleifer 2014; Amromin and Sharpe,2014). Therefore, investors should be always more likely to lock in gains during bust than during boom cycles - irrespectively of the time stage of the cycle. Adding to this, Weber, Weber, and Nosic (2013) find that investors are most pessimistic about future market returns at the beginning of a downturn. Thus, PGR should be highest at the beginning of a bust period and then decrease over time. Moreover, if bust investors are more pessimistic and the level of pessimism is highest at the beginning and decreases throughout the cycle, we should find differences in PGR across cycles to become smaller since differences in beliefs narrow down. As previous literature shows (e.g. Kuhnen, Rudorf, and Weber, 2017; Eil and Rao, 2011), investors tend to update their beliefs more from information which is consistent with their prior choices. Since asset that decreased in value, i.e. assets trading at a loss, are not in line with investors' prior investment decision, the effect of the belief channel on loss realizations should be limited.

Turning to the results of our timing analysis, we find that - over the whole cycle duration - bust investors are always more likely to realize their gains than boom investors. This is consistent with bust investors being more pessimistic about future returns which makes them locking in their gains as early as possible. Within bust periods, we observe that PGR is 30 percent higher at the beginning than at the end which is consistent with investors being most pessimistic at the beginning of a financial market downturn. Further, we find that the difference in PGR across cycles decreases over time but remains highly statistically significant: Investors are 29 percent more likely to sell an asset trading at a gain in an early stage of a bust period than in an early stage of a boom period, whereas, investors are only 15

\footnotetext{
${ }^{6}$ By timing we mean does the investor sell assets right at the beginning, in the middle, or at the end of a cycle.
} 
percent more likely to sell an asset trading at a gain in an advanced stage of a bust period than in an advanced stage of a boom period - which is in line with converging beliefs. Turning to the realization of loss assets over time, we find difference across and within cycles to be less strong and hardly economically significant.

In a recent paper An, Engelberg, Henriksson, Wang, and Williams (2019) find that investors who hold a portfolio with an overall positive value do not experience a disposition effect, while investors holding a portfolio with an overall negative value do. Since it is plausible to assume that an investor's portfolio value and stock market conditions are positively correlated, one might argue that our results are driven by changes on the portfolio and not by changes on the stock market level. In the robustness section, we show that market cycles affect investors' selling behavior even after controlling for the portfolio driven disposition effect. While the portfolio driven disposition effect affects the level of the disposition effect, the difference in the disposition effect across market cycles remains unaffected. Hence, both effects impact investors' strength of the disposition effect. We further show that that our results are also robust to different definitions of boom and bust periods: Employing more reactive boom-bust measures and/or restricting our sample to the most extreme market phases, our main result remains unchanged. Additionally, we show that mechanics such as an increased number of gain assets in a boom period (relative to bust periods) do not drive our results.

Collectively, our findings cast doubt on the indirect assumption that the disposition effect is a time independent phenomenon. Taking up literature arguing that investors' preferences and beliefs vary with stock market cycles, we find that the disposition effect moves countercyclical to the stock market, i.e. is low in boom periods and high in bust periods. This change in investors' selling behavior across cycles is mainly driven by their increased gain realization in bust markets and can be linked to changes in preferences, as well as changes in belief of individual investors.

Our paper adds to existing literature that has examined stock-level attributes associated with retail investors' selling behavior. While other researchers examine how positive returns (e.g. Shefrin and Statman 1985, Odean, 1998), demographics (e.g. Dhar an Zu, 2006), geographic proximity (Coval and Moskowitz, 1999) or the choice of the asset classes (Chang, Solomon, and Westerfield, 2016) shape investors' selling behavior, our study 
demonstrates that the level of the disposition effect is strongly affected by financial market cycles. Further, our findings highlight the importance of the choice of the sample period in studies investigating retail investors' selling behavior. So far, most studies dealing with the disposition effect use data from boom periods (see Appendix A Panel 2). Since retail investors suffer from a lower disposition effect in boom periods, literature on average might underestimates the level of the disposition effect. Moreover, we are able to link changes in the disposition effect across financial market cycles to changes in investors' preferences and belief. Thereby, we add to the longstanding discussion on what drives the disposition effect (e.g Odean, 1998; Kaustia, 2010; Ben-David and Hirshleifer, 2012). As our results show both proposed drivers, preferences and beliefs, affect the strength of the disposition effect.

\section{Data}

The study is based on four data sets. The first data set contains the trading history of 98,880 randomly drawn investors who hold accounts at a large German online bank from January 2001 until December 2015. ${ }^{7}$ Trades are reported on a daily frequency. Overall, the trade file includes more than 20 million records. Each record provides the date of purchase/sale, the purchase/selling price, the volume traded, and the respective fees. The second data set contains investors' portfolio holdings. It consists of monthly positions for all accounts during the sample period. Each of the approximately 96 million records provide information about the account number, security number, year, month, the position's market value, and the position's quantity. Accounts that are closed during the sample period are not replaced. In addition to investor's trading and holding data, the third data set contains information about investor's demographics such as age, gender, income, and zip code. The fourth data set contains daily market data (from Thomson Reuters Datastream) of all the securities held or traded by the investors who are part of the first and second data set during the observation period.

According to Odean (1998) and Ben-David and Hirshleifer (2012), we filter the raw data set as follows: First, the analysis includes only securities that are identified as common

\footnotetext{
${ }^{7}$ The data set has been used in other studies, e.g. Schmittmann, Pirschel, Meyer, and Hackethal (2015) and Laudenbach, Loos, Pirschel, and Wohlfahrt (2020).
} 
shares that can be matched to market data downloaded from Thomson Reuters Datastream. Second, if an investor's trading history shows multiple trades in one security per day the transactions are netted. Third, we exclude securities that are purchased before January 2001 because the purchase prices of these assets are unknown and thus the disposition effect cannot be calculated. We confine our analysis to non-advised investors. We then construct each investor's portfolio on a monthly basis and calculate investors' disposition effect. Consistent with Odean (1998) and Chang et al. (2016), we only focus on observations in months when a sale takes place in an investor's portfolio. ${ }^{8}$ We end up with 80,860 investors in the boom period and 69,439 investors in the bust period. A bust period takes place whenever the excess (of risk-free rate) cumulative CDAX return in the past 24 months is negative and zero otherwise (Daniel and Moskowitz, 2016). Information which month is being categorized as boom or bust month can be found in Appendix B. Overall, our data contains $18,280,493$ records from January 2001 up to December 2015. Detailed information about the sample composition in boom and bust months is depicted in Table 1.

\section{[Insert Table 1 here]}

On the portfolio level, we observe significant differences in boom and bust periods in terms of the average number of monthly trades, the fraction of portfolio holdings trading at a gain or loss, and realized returns. While the difference in the average number of monthly trades is highly significant, it is rather small in magnitude: The absolute difference in average number of monthly trades is only 0.19. As can be expected, we find that an investor's portfolio contains more gain assets in boom than in bust periods, i.e. the fraction of gain assets almost doubles in boom periods compared to bust periods (40.73\% versus $28.69 \%$ ). Likewise, we find that an investor's portfolio contains more loss assets in bust than in boom periods, i.e. the fraction of loss assets in boom and bust periods equals $59.27 \%$ and $71.31 \%$, respectively. Note, that for calculating the fraction of gain (loss) assets in an investor's portfolio, we simply count the absolute number of gains (losses) assets and divide this by the number of all assets the investor holds in his portfolio in this particular month. We further find that realized gains

\footnotetext{
${ }^{8}$ In an unreported analysis, we test if this sample restriction alters our results. We find that PGR increases by $25 \%$ in bust compared to boom periods and that the disposition effect in bust periods is about $95 \%$ higher than in boom periods. This fits our main results using the filtered data in section 4 .
} 
(losses) in boom periods are 7.73 (7.92) percentage points higher (less negative) than realized gains (losses) in bust periods. We do not find statistically significant differences in the average number of stocks held or in investors' portfolio diversification (measured by the HerfindahlHirschman Index (HHI)) across boom and bust markets. The average investor in our sample holds 10 stocks and has an $\mathrm{HHI}$ around 35\%. This is in line with researchers finding the $\mathrm{HHI}$ of portfolios with more than 11 stocks to range around 33\% (Ivković, Sialm, and Weisbenner, 2008). To account for differences on the portfolio level, we control for potential portfolio driven effects such as the portfolio driven disposition effect (An et al., 2019) and the number of paper gains in our robustness tests.

Turning to the investor level, differences between boom and bust periods become smaller. There is no difference in the level of investors' education. The difference in age and gender across financial market cycles is statistically significant at the one percent level, however, it is small in magnitude. The average investor in our sample is male and is in his early 50ths. To account for differences on the investor level, we use investor and investormonth fixed effects in our regressions.

\section{Methodology}

While Odean (1998) proposes a simple proportion-based measure to calculate the disposition effect thereby neglecting other variables affecting the disposition effect, Birru (2015) developes a regression equation approach to control for other variables driving investors' selling behavior. The standard regression specification for measuring the disposition effect (Birru, 2015; Chang et al. 2016) uses the following equation:

$$
\text { (1) } \text { Sale }_{i j t}=\beta_{0}+\beta_{1} \text { Gain }_{i j t}+\epsilon_{i j t}
$$

where observations occur at the investor (i), stock (j), and month (t) level. Sale is a dummy variable that equals one if the volume of asset $j$ decreases between the previous month and today in investor i's account, and zero otherwise. Thus, we include total as well as partial sales in our analysis. Gain is a dummy variable that is equal to one if the value-weighted average purchase price of stock $j$ is smaller than the current market price of stock $j$, and zero 
otherwise. In line with literature (e.g. Odean, 1998), we do not consider fees and commissions paid on each transaction when calculating the value-weighted average purchase price. In cases in which an investor sells off a position entirely and later repurchases the same security, the average purchase price is set to zero upon the total sale of the position. Consistent with literature (e.g. Odean, 1998; Chang et al., 2016), we report gains and losses in each month in which a sale takes place in an investor's portfolio. Chang et al. (2016) argue that in months without a sale, investors' behavior might be driven by deliberate choice or simple inattention. They show that limiting the sample to months with at least one sale does not drive their results.

In regression (1), the constant $\left(\beta_{0}\right)$ measures investors' propensity to sell a stock at a loss (PLR), whereas, the sum of the constant and the gain coefficient $\left(\beta_{0}+\beta_{1}\right)$ measures investor's propensity to sell a stock at a gain (PGR). Hence, $\beta_{1}$ measures the disposition effect (PGR - PLR).

Since we want to investigate if financial market cycles have an impact on the selling behavior of private investors, we add a boom indicator into the traditional disposition effect regression. We analyze the effect of financial market cycles on investor's selling behavior by running the following regression equation:

(2) Sale $_{i j t}=\beta_{0}+\beta_{1}$ Gain $_{i j t}+\beta_{2}$ Boom $_{t}+\beta_{3}$ Gain $_{i j t} \times$ Boom $_{t}+X \beta^{\prime}+\epsilon_{i j t}$

where observations are again on the investor-stock-month level. Following Daniel and Moskowitz (2016), we use a Boom dummy that equals one if the excess (of risk-free rate) cumulative CDAX return in the past 24 months is positive and zero otherwise. All following boom/bust specifications are based on the CDAX because we use German retail investor data. However, results are robust to using the $\mathrm{MSCl} A C W I$ (see Appendix $\mathrm{C}$ ). The correlation between $\mathrm{CDAX}$ and $\mathrm{MSCl} \mathrm{ACWI}$ during our sample period is equal to 0.763 . In the robustness section (see 6.2) we further show that our main result remains highly significant when using alternative non-financial market boom/bust indicators such as the NBER recession indicator. $X$ is a vector of control variables known to affect investors' selling propensities (e.g. Ben-David and Hirshleifer, 2012). These control variables comprise the holding period, weighted-average 
purchase price, returns (positive and negative), and the interaction between holding periods and return. In more detail, holding period is the square root of the number of months since the purchase of the position; the weighted-average purchase price is the natural logarithm of the weighted-average purchase price; and return positive or negative is the return since purchase if it is positive or negative, respectively.

Our coefficient of interest in regression ( 2 ) is $\beta_{3}$. The coefficient of the interaction term represents the difference in the disposition effect between boom and bust markets. Moreover, regression (2) enables us to calculate investor's propensity to sell a stock at a gain (PGR) and loss (PLR) within boom and bust periods. Investors' PGR in boom and bust periods is calculated by summing up all regression coefficients $\left(\beta_{0}+\beta_{1}+\beta_{2}+\beta_{3}\right)$ and by adding up $\beta_{0}$ and $\beta_{1}$, respectively. $\beta_{0}+\beta_{2}$ and $\beta_{0}$ give us investors' PLR in boom and bust periods.

Because investors' selling decisions are most likely serially and cross-sectionally correlated, we cluster standard errors at the investor and month level in all regressions. We further run several models using investor and month fixed effects to capture the aggregate effect of all unobservable, time-invariant explanatory variables on an investor's selling behavior. This is essential since unobservable variables such as an investor's characteristics (investor level) and seasonal trading patterns (month level) might affect our results.

\section{The disposition effect across market cycles}

Figure 1 depicts graphically the result we document in this paper: The disposition effect moves countercyclical with the financial market index. We further empirically investigate this relationship by running regression (2). In regression (2) we estimate the average difference in the disposition effect across boom and bust periods. The results are reported in Table 2a. In column 1, we present our baseline result using no fixed effect but two-way clustered standard errors. In column 2 and 3, we successively add investor and month fixed effects to our baseline regression specification. In column 4, we include control variables which researchers find to affect investors' selling behavior (e.g Ben-David and Hirshleifer, 2012). Simplifications of the results from regression equation (2) can be found in Table $2 b$.

Analyzing Table $2 \mathrm{a}$, we directly see that our coefficient of interest $\left(\beta_{3}\right)$ is always negative and statistically significant with a p-value of less than one percent: Investors show a 
consistently higher disposition effect in bust than in boom periods. The regression in Model 1 Table 2 a shows that on average the disposition effect in boom periods is $5.42 \%$, while in bust periods it is $10.6 \%$. Thus, the disposition effect is nearly twice as high in bust periods. In absolute terms, the difference in the disposition effect between boom and bust periods equals 5.18 percentage points. This effect is robust and holds even after introducing investor fixed effects (see Model 2). Hence, our main result is not driven by certain investor groups. To ensure that our results are not driven by different investor groups being active in boom and bust period, we further introduce investor-month fixed effects to our model (Model 3). Results remain unaffected. The gain-boom interaction term equals $-4.83 \%$ and is statistically significant at the one percent level. In Model 4, we further introduce control variable which researchers find to affect investors' selling propensities (e.g. Ben-David and Hirshleifer, 2012) to our framework. The difference in the disposition effect across boom and bust markets remains strongly statistically significant. Indeed, controlling for holding period, weightedaverage purchase price and returns (positive and negative), the difference between the disposition effect in boom and bust is strongest among all our model specifications and equals 5.74\%. Across all models, the difference in the disposition effect between boom and bust periods varies between 4.17 and 5.74 percentage points, with the difference always being highly statistically significant.

\section{[Insert Table 2 here]}

Since the disposition effect is the difference between PGR and PLR, either changes in gain realization and/or loss realization can drive our main result. Analyzing the difference in the disposition effect between boom and bust periods in more detail, we find that differences in the selling behavior are mainly driven by the gain side. In bust periods, investors' propensity to sell a gain asset is equal to $23.90 \%$. In contrast, the likelihood to sell a gain asset in boom periods is only $18.90 \%$. Hence, investors are in absolute terms 5 percentage points more likely to sell their gains in bust rather than in boom periods. This difference is highly statistically significant at the one percent level. Turning to changes in investors' PLR across financial market cycles, we find changes in PLR to be insignificant. The difference in realizing a loss in boom versus bust periods is depicted by the boom coefficient $\left(\beta_{2}\right)$. Investors are only 0.184 percentage points less likely to realize losses in bust than in boom periods. However, this difference is neither quantitatively nor statistically significant. After introducing investor fixed 
effects to our regression, the difference in investors' loss selling behavior becomes statistically significant. The boom coefficient increases in both, magnitude and significance, indicating that investors' characteristics affect the loss selling behavior. However, compared to the differences in PGR across stock markets cycles, changes in PLR are neglectable. Thus, the gain side is the main driver of our results.

Overall, the results from regression equation (2) support our descriptive evidence from Figure 1. The disposition effect is almost twice as high in bust periods relative to boom periods and this is mainly driven by investors' increased gain realization in bust periods.

One might argue that an investor's portfolio will per se contain more gain assets in boom periods than in bust periods and thus PGR in bust periods is higher than PGR in boom periods since PGR purely measures the fraction of realized gains over all gains in an investors' portfolio. Therefore, the observed difference in PGR between boom and bust markets may not reflect a change in investors' selling behavior but may rather be mechanically driven. For example, think of an investor who always sells exactly one asset per month. If the number of paper gains in the investor's portfolio increases, PGR will decrease, whereas, if the number of paper gains decreases, PGR will increase. Since the number of gains in an investor's portfolio will increase in boom and decrease in bust periods, this investor will show a higher PGR in bust than in boom periods even though his selling behavior did not change with market cycles. To ensure that our results are not driven by such mechanics, we run our baseline regression (2) while controlling for the absolute number of paper gains on the market and the individual's portfolio. As can be seen in Appendix D, after controlling for the number of paper gains the difference in disposition effect across market cycles is still economically and statistically significant. Compared to our baseline results from Table 2, the regression coefficients on the interaction of gain and boom (5.40\% or $5.57 \%)$ become even more negative.

Since we are the first to report a countercyclical movement of the disposition effect with the market and since we are using a proprietary data set, one might cast doubt on the representativeness of our results. Our data set differs from the classical Odean (1998) data set in two aspects: We deal with German investors instead of U.S. investors and we analyze data from 2001 to 2015 instead of analyzing data from the 1990's. Hence, differences between U.S. and German investors and/or different time periods might affect our results. By running the standard disposition effect regression (i.e. equation (1)), we show that our results 
are comparable to other studies. As depicted in Table 3 column (1), on average a German investor suffers from a disposition effect of $6.83 \%$. The average investor sells a gain with probability one-fifth (20.33\%) and sells a loss with probability $13.5 \%$. The ratio of selling a gain versus selling a loss is equal to 1.5 .

\section{[Insert Table 3 here]}

These results are in line with the literature on the disposition effect. For example, Odean (1998) finds that the U.S. investors' disposition effect in the 1990's ranges between $5 \%$ and $8 \%$ and that the ratio of PGR and PLR is equal to 1.5. Moreover, our results are also in line with German disposition effect studies. Using German trading data from January 1991 to May 2000, Dorn and Strobl (2009) show German investors have a disposition effect of $7.7 \%$ and that the ratio of PGR/PLR is 1.52. Thus, the results seem not to be driven by country or time specific features of our data set and can be considered externally valid.

\section{Selling pattern in boom and bust periods}

\subsection{The effect of changes in risk aversion}

We find that the change in the disposition effect between boom and bust periods is mainly driven by investors' change in gain realization across financial market cycles. The question at hand is if changes in investors' preferences, i.e. changes in risk aversion, can explain our finding. As previous experimental studies show, investors' risk aversion increases in bust periods (e.g. Cohn et al., 2015).

Throughout this paper, investors have prospect theory (PT) preferences. Investors with prospect theory preferences base their decisions on relative rather than on absolute wealth changes (i.e. investors evaluate against a reference point), are risk-averse over the gain domain (concave value function) and risk seeking over the loss domain (convex value function), are more sensitive to losses (i.e. loss aversion) than to gains, and tend to overweight (underweight) small (large) probabilities (i.e. probability weighting). The question at hand is how a change in investor's risk aversion affects the investor's decision of selling versus holding on to a risky asset. 
To illustrate the effect of risk aversion, consider an asset with a normally distributed return, an expected value of $12 \%$, and a standard deviation of $25 \%$ (as in Kaustia, 2010). The PT investor has the following value function:

$$
\text { (3) } v(x)=\left\{\begin{array}{r}
x^{\alpha}, \quad x \geq 0 \\
-\lambda(-x)^{\beta}, x<0
\end{array}\right.
$$

where $\alpha$ and $\beta$ are coefficients of risk aversion and risk seeking, $x$ is the return of an asset with respect to the reference point, and $\lambda$ is the coefficient for loss aversion. Using experimental data, Tversky and Kahneman (1992) estimate $\lambda$ to be 2.25 and $\alpha$ as well as $\beta$ to equal 0.88. If an investor sells a risky asset, she will obtain a certain value $v(x)$. The PT value of holding on to a risky asset is determined by taking the expectation of the value function over the distribution of the risky asset return (with respect to the reference point):

(4) Prospect value of holding $=\int_{-\infty}^{+\infty} v(x) p(x) d x$,

with $p(x)$ being the probability density function of the return with respect to the reference point. Note, that in our example we do not address probability weighting. Therefore, investors' subjective decision weights are equal to the objective probabilities. This simplification is admissible since probability weighting becomes particularly important once the return distribution is heavily skewed, i.e. not symmetric (Barberis, 2012; Imas, 2016). Investor's decision problem, i.e. selling versus holding on to the risky asset, can be formalized by subtracting the PT value of holding on to the risky asset from the value of selling the risky asset. If the difference is positive (negative), an investor will sell (hold on) the asset.

Since we want to investigate the effect of changes in risk aversion on investors' selling versus holding decision, we now analyze investor's decision problem for two investors ( $A$ and B) who solely differ in their coefficients of risk aversion, i.e. alpha. Investor A's preference parameterization mirrors the median subject from Tversky and Kahneman (1992): $\alpha=0.88$, $\beta=0.88$ and $\lambda=2.25$. Investor $B$ is assumed to be more risk-averse than investors $A$. Thus, investor B's value function over gains shows a stronger curvature than investor B's value 
function over gains implying investor B's alpha to be lower than investor A's alpha. Holding everything else equal, we assume Investor B's preference parameterization to be $\alpha=0.5$, $\beta=0.88$, and $\lambda=2.25$. The choice of $\alpha=0.5$ is in line with $\mathrm{Wu}$ and Gonzalez (1996) and Ingersoll and Jin (2013).

Now consider that both investors hold the risky asset (described above) in their portfolio. ${ }^{9}$ If the value of the asset falls by $10 \%$ and thus trades in the loss domain, both investors want to hold on to the risky asset. The value of selling the risky asset equals -17.07 and is the same for investor $A$ and $B$ since the value function over losses does not depend on alpha. However, the PT value of holding on to the risky asset differs between investors. As Kaustia (2010) points out, if the value decreases by $10 \%$ the distribution of the risky shifts to the left by $10 \%$ and therefore investor A's (investor B's) PT value of holding on to the loss asset has a value of $-6.35(-11.54)$. Thus, both investors are better off holding on to the asset. Now, what happens if the risky asset trades in gain domain? If the value of the asset increases by $10 \%$ investor $A$ prefers holding on to the asset, whereas the more risk-averse investor $B$ wants to sell the asset. Selling the asset after a $10 \%$ increase in value yields a value of 7.59 and 3.16 for investors $A$ and $B$, respectively. The prospect value of holding on to the risky asset for investor A (investor B) is 11.84 (0.07). Therefore, investor A prefers holding on, whereas, investor B prefers selling the asst after a $10 \%$ increase in value. This numerical example nicely illustrates that differences in alpha among investors can induce differences in investors' selling pattern for an identical asset: If the asset is trading at a loss of $10 \%$ both investors prefer holding on to the risky asset, whereas, if the asset trades at a gain of $10 \%$ the more (less) risk-averse investor prefers selling (holding on to) the risky asset.

We can further generalize this example by plotting investor's decision problem (selling versus holding) as a function of returns relative to investors' reference point. Figure 2 depicts the decision problem as a function of return for investor $\mathrm{A}(\alpha=0.88$, dashed line) and

\footnotetext{
${ }^{9}$ Note, that the PT value of buying the asset is positive (3.37) for investor A and negative (-4.76) for investor B, i.e. investor $A$ would buy the asset whereas investor B would not buy the asset in the first place. Since we want to analyze the effect of a change in risk aversion on investors' selling behavior, our main concern is not when the investor bought the asset.
} 
investor $\mathrm{B}$ ( $\alpha=0.5$, solid line). For consistency, we use the same risky asset distribution and preference parameter values as before to construct Figure 2 .

\section{[Insert Figure 2 here]}

Figure 2 shows that a decrease in alpha, i.e. an investor becomes more risk-averse, leads to an upward shift of the function. Holding the return magnitude constant, the more risk-averse investor shows a higher propensity to sell a risky asset trading at a gain or loss than the less risk-averse investor. The difference in selling behavior between more and less risk-averse investors is stronger for assets that increased in value than for assets that decreased in value. The reason is that differences in alpha affect investor's decision problem in the gain domain through the PT value of holding on to the asset and the value of selling the asset today. Yet, in the loss domain, differences in alpha affect investor's decision problem solely through the PT value of holding on to the asset. Therefore, changes in investors' risk aversion will particularly drive differences in their gain realization rather than loss realization behavior.

These theoretical predictions fit our empirical results from the section 4. According to experimental research (e.g. Cohn et al., 2015), investors are more risk-averse in bust than in boom periods. Thus, the less-risk averse investor $A$ depicts a boom investor while the more risk-averse investor $B$ represents a bust investor. Theory predicts that the difference in the level of risk-aversion throughout financial market cycles translates into differences in investors' selling behavior - for which we find empirical evidence. Moreover, we find that differences in selling behavior are driven by investors' changes in gain realization rather than loss realization. The asymmetric effect of realizing gains and/or losses can also be linked to theory. As outlined above, a change in alpha affects the investor's decision problem in the gain domain through the value of selling and the value of holding on to the asset, whereas, in the loss domain, a change in alpha only affects the value of holding on to the risky asset.

While we find empirical evidence that there is heterogeneity in investors' selling behavior in boom and bust periods on average, theory further predicts that holding the magnitude of a gain/loss constant, a risk-averse investor shows a higher propensity to sell a risky asset trading at a gain or loss than the less risk-averse investor. This prediction is illustrated by the upward shift of the function due to a decrease in alpha (see Figure 2). The 
question at hand is whether we can find empirical evidence for such and upward shift. To test for this prediction, we constrain our sample to risky assets that experience at least one boom and one bust period in an investor's portfolio and introduce investor as well as security fixed effects to our model. This allows us to analyze an investor's selling behavior within a specific asset that is held in both financial market cycles. Since we want to investigate investors' selling behavior over a wide range of returns, we replace the dummy variable gain in our main regression equation (2) by return interval dummy variables ranging from $-30 \%$ to $+30 \%$ return, in two percentage point increments. Returns smaller (bigger) than $-30 \%(+30 \%)$ are subsumed in the extreme $-30 \%(+30 \%)$ return interval. To avoid a large number of interaction terms, we run the regression equation for boom and bust cycles separately. Figure 3 graphically depicts the results from the formal regression analysis which can be found in Appendix E. The solid (dashed) line depicts the bust (boom) investor's propensity to sell an asset.

\section{[Insert Figure 3 here]}

Using our German retail investor trading data set, we find empirical evidence for an upward shift of the investor's decision problem function: The solid line is always above the dashed line - irrespective of the gain's/loss's magnitude. A more risk-averse investor (i.e. a bust investor) is always more likely to sell both, a gain and a loss, than a less risk-averse investor (i.e. a boom investor). Consistent with theory, we further find that differences in PGR and PLR between boom and bust investors are stronger for assets trading in the gain than assets trading in the loss domain.

Collectively, the observed investor behavior is in line with a preference-based explanation of the disposition effect. Differences in investors' selling pattern of gains in boom and bust periods can be linked to an increase in investors' risk aversion during bust periods (e.g. Cohn et al., 2015).

\subsection{The role of time}

Besides changes in investors' risk aversion, researcher suggest changes in investors' beliefs as another potential driver of the disposition effect. Since investors' beliefs are positively correlated with past stock market returns (Weber et al. 2013; Greenwood and Shleifer, 2014; Amromin and Sharpe, 2014), investors become overly pessimistic (optimistic) about future returns in bust (boom) markets. 
To investigate how changes in beliefs affect investors' selling behavior, we look at the timing of sales within and across boom and bust cycles. If investors face a bust period, they are assumed to be more pessimistic about future returns. Therefore, investors should always be more likely to lock in their gains during market downturns than during market upswings. Using survey data, Weber et al. (2013) further show that investors are most pessimistic about future market returns at the beginning of a downturn and thus PGR should be highest at the beginning of a bust period. Moreover, the difference in gain realization should be most severe at the beginning of boom and bust periods since investors are (overly) optimistic versus (overly) pessimistic, respectively. Over time, this difference in beliefs should narrow down translating into smaller differences in investors gain realization in boom and bust. We do not expect to find strong differences in investors' PLR in boom and bust periods over time. As previous literature shows (e.g. Kuhnen, Rudorf, and Weber, 2017; Eil and Rao, 2011), investors tend to update their beliefs more from information which is consistent with their prior choices. Since asset that decreased in value are not in line with investors' prior investment decision, the effect of the belief channel on loss realizations should be limited.

\section{[Insert Figure 4 here]}

In a first step, we plot PGR and PLR in boom and bust periods over time (see Figure 4). To account for different time lengths of boom and bust cycles during our observation period, we subdivide each cycle into deciles. Observations in an early state of a cycle are sorted into decile 1 and towards the end of a cycle observations are sorted into decile 10 . Due to this time partition the minimum length of a cycle has to be at least 10 months. The medium length of a boom (bust) period is 31 (34) months and observations are aggregated over cycles (i.e. boom or bust).

As illustrated in Figure 4, within a bust cycle, investors are most likely to sell their gains at the beginning of the market downturn. Speaking in numbers, investors are $45 \%$ more likely to sell a gain at the beginning (decile 1 ) than at the end (decile 10) of the bust period. Further, Figure 4 shows that differences in PGR across financial market cycles are strongest at the beginning and decrease over time. While in decile 1 the difference in PGR in boom and bust cycles equals around 7 percentage points it decreases up to 3 percentage points in decile 10 . 
To investigate this relationship more formally, we introduce time dummy variables to regression equation (2) and estimate the following regression equation:

$$
\begin{aligned}
& \text { (5) } \text { Sale }_{i j t}=\beta_{0}+\beta_{1} \text { Gain }_{t}+\beta_{2} \text { Boom }_{t}+ \\
& \beta_{3} \text { Intermdiate }_{t}+\beta_{4} \text { Advanced }_{t}+X \beta^{\prime}+\epsilon_{i j t}
\end{aligned}
$$

where observations occur at the investor (i), stock (j), and month (t) level. The Sale and Boom variables are defined as in regression equation (2). To track investors' selling behavior within market cycles over time, we decompose each market cycle intro three periods: early, intermediate, and advanced state. Early (Advanced) is a dummy variable that equals one if the observation belongs to the first (last) three months of a boom or bust period. Intermediate is a dummy variable that is equal to one if an observation is not part of the Early or Advanced state. Early as base category is subsumed in the constant. ${ }^{10} \mathrm{X}$ is a vector of interaction terms. Note, that we do not assume investors to be able to time the market. To investigate investors' selling behavior over time, we require the length of a cycle should at least be six months. As depicted in Appendix B, a few cycles do no satisfy this requirement. This reduced the number of observations by $3 \%$ (relative to base sample from Table 2). Standard errors are again twoway clustered at the investor and date level and we include investor fixed effects. To ensure that our results are not affected by changes in the absolute number of assets in an investor's portfolio over time, we further control for the number of assets in an investors' portfolio throughout every regression equation specification. Regression results are shown in Table 4a. A summary of regression results is given in Table $4 \mathrm{~b}$.

\section{[Insert Table $4 a$ and $4 b$ here]}

Let's first look at investors' gain realization over time and across cycles. In each time stage (i.e. early, intermediate, advanced), investors are always more likely to sell a gain in a bust period than in a boom period. This difference decreases over time but remains highly statistically significant. Investors are 6.29 percentage points (29 percent) more likely to sell an asset trading at a gain in an early stage of a bust period than in an early stage of a boom

\footnotetext{
${ }^{10}$ An alternative time partition of boom and bust periods using quartiles can be found in Appendix $F$.
} 
period, whereas, investors are only 2.63 percentage points (15 percent) more likely to sell an asset trading at a gain in an advanced stage of a bust period than in an advanced stage of a boom period. These findings are in line with our hypotheses that pessimistic investors, i.e. bust investors, are always more likely to lock in their gains as more optimistic investors, i.e. boom investors. Bust investors' PGR is highest at the beginning of a bust period and then decreases over time which is in line with survey evidence showing that investors' expectations are most pessimistic at the beginning of a market downturn (Weber et al., 2016). Our results are not affected by the introduction of investor fixed effects.

Turning to investors' loss realization over time and across cycles, we find differences to be less strong. On average, investors are slightly more likely to sell a loss asset in a bust cycle than in a boom cycle. This difference is mainly driven by investors being 3.2 percentage (see coefficient of boom dummy variable) points more likely to sell a loss asst at an early stage of a bust period than at an early stage of a boom period. Over time, this selling behavior of losses flips around, meaning that investors' PLR in an intermediate and advanced stage of a boom is higher than investors' PLR in an intermediate and advanced stage of a bust. However, this finding is only significant when using investor fixed effects and it is hardly economically significant. Our results show that investor react less strong to changes in financial market cycles when an assets trades in the loss domain which is consistent with literature arguing that investors do not like to update their beliefs if the new information is inconsistent with their prior choices (e.g. Kuhnen, Rudorf, and Weber, 2017; Eil and Rao, 2011).

Collectively, the observed differences in investors' selling pattern over time within and across market cycles can be linked to changes in investors' beliefs across financial market cycles. Differences in investors' selling behavior across financial markets are more pronounced for assets trading at a gain than assets trading at a loss.

\section{Robustness test}

\subsection{The disposition effect at the portfolio level}

A recent study by An et al. (2019) finds that investors who hold a portfolio with an overall positive portfolio value do not exhibit a disposition effect, while investors holding a portfolio with an overall negative value do so. It is plausible to assume that there is a link between the value of an investor's portfolio and market cycles. In boom periods, one would 
expect to see the majority of investors holding a portfolio with an overall positive value, while, in bust periods, one would expect it to be the other way around. Hence, our results might be driven by changes at the investors' portfolio level but not by changes in financial markets. To control for this alternative explanation, we run regression equation (1) on two subsamples: (Panel A) portfolio trading at a gain in a boom market and (Panel B) portfolio trading at a gain in a bust market. If the portfolio driven disposition effect - and not changes in financial market cycles - is the underlying source of the difference in the disposition effect across market cycles, then there should be no disposition effect in any of the two subsamples since both portfolios are trading at a gain.

\section{[Insert Table 5 here]}

As shown in Table 5, the disposition effect in Panel A is insignificant (0.24\%), whereas, the disposition effect is highly significant for Panel B (5.38\%). This result is robust and holds for all model specifications. Interestingly, comparing results from Table 2 column (1) (sample without restriction on portfolio value) and results from Table 5 column (1) (sample conditioned on portfolio value being positive), we find that the overall level of the disposition effect decreases from the unrestricted to the restricted sample, however, the absolute difference between the disposition effect in boom and bust markets remains rather constant across samples. In the unrestricted sample investors' disposition effect in boom (bust) markets is $5.42 \%(10.60 \%)$, whereas, in the restricted sample, investors' disposition effect in boom (bust) markets is $0.24 \%$ (5.38\%). Thus, the change in investors' selling behavior across boom and bust markets equals approximately 5.1 percentage points in both samples. This clearly shows that financial market cycles do have an impact on investors' selling behavior even after controlling for portfolio level effects. Collectively, both effects seem to affect investors' strength of the disposition effect.

\subsection{Sensitivity of the boom definition}

Our main analysis relies on the commonly used boom and bust classification by Daniel and Moskowitz (2016). To confirm that our results are robust, we test several alternative boom and bust classifications. 
As a first alternative measure (Model 1) we define a boom dummy at month t equal to one if the excess (of risk-free rate) cumulative CDAX return in the past 12 months is strictly greater than zero. This is different from the Daniel and Moskowitz (2016) boom dummy indicator where the excess (of risk-free rate) cumulative CDAX return in the past 24 months is strictly greater than zero. Shortening the time period will make Model 1 more reactive towards fluctuations in the stock market.

In Model 2 the boom dummy equals one if the excess cumulative 12 months lagged CDAX return falls into the top $30 \%$ of the market return over our sample period. The boom dummy is zero if the 12 months lagged return of the CDAX falls into the bottom $30 \%$ of the market return. If the return falls neither into the top nor bottom category, the dummy Neutral equals one. Model 2 introduces a third market phase (boom, bust, neutral) into our framework. Thereby, we ensure that our results are caused by trades in the extreme market phases rather than by trades in neutral market phases. In Model 3 the boom dummy equals one (zero) if the excess (of risk-free rate) cumulative CDAX return in the past 12 months is greater (small or equal) than zero for at least three months in a row. Model 3 combines the main features of Model 1 and Model 2. For Model 2 and Model 3 regression equation (2) has to be modified because the alternative boom definitions in these models allow each month $t$ to be either a boom, bust, or neutral month. To account for months that are neither boom nor bust month (i.e. neutral months) the regressor Neutral and the interaction term Neutral XGain are added to regression equation (2).

Lastly, Model 4 uses the bust period definition of the National Bureau of Economic Research (NBER) which focuses on macroeconomic rather than financial market cycles. Since we use German investor data, the boom dummy is equal to zero if the German GDP decreases in two consecutive quarters. By using the NBER recession indicator, we test if our main result is a pure stock market phenomenon or if it can be extended to general macroeconomic movements. We rerun our main regression equation (2) using all alternative definitions. Results are displayed in Table 6.

\section{[Insert Table 6 here]}

As shown in Table 6, the difference in the disposition effect across stock market cycles is not sensitive to changes in the definition of boom and bust periods. Our main result holds 
even if we allow the boom/bust indicator to become more reactive (Model 1), restrict the sample to the most extreme market phases by introducing a neutral market phase (Model 2), and use non-financial boom/bust indicators. The change in the disposition effect is again displayed by the Gain-Boom interaction term. The difference in the disposition effect across financial market cycles ranges from -6.33 percentage points (Model 2) to -2.22 percentage points (Model 4). Models 1 to 3 use a stock market based boom/bust definition and show that the magnitude of our coefficient of interest in our baseline regression (2) (-5.18 percentage points) fits well within in the range of the alternative definitions. Model 4 is based on the NBER boom/bust definition that focuses on changes in German GDP as a measure of macroeconomic trends. Even though macroeconomic cycles react more slowly to changes of economic conditions than financial market cycles (see Appendix B) our effect persists.

\section{Conclusion}

While the disposition effect is one of the most explored phenomena in behavioral finance, researchers investigating the disposition effect use data that mostly cover boom periods and implicitly assume that the disposition effect is constant over time. However, proposed drivers of the disposition effect (preferences and beliefs) are found to be rather countercyclical.

We use novel data that contains trade records and portfolio holdings of approximately 100,000 private investors in Germany throughout several boom and bust markets (20012015) and show that the disposition effect is not constant over time. In particular, we demonstrate that the disposition effect moves countercyclical with the financial market, i.e. is low in boom markets and high in bust markets. These differences in the disposition effect across financial market cycles are mainly driven by investors' increased gain realization in bust periods compared to boom periods. Investors are 5 percentage points (26 percent) more likely to realize a gain in bust than in boom periods. We find evidence that both, preferences (i.e. being more risk averse in bust than in boom markets) and beliefs (i.e. being more pessimistic in bust than in boom markets), affect investors' selling behavior across financial market cycles.

Collectively, our findings cast doubt on the indirect assumption that the disposition effect is a time-independent phenomenon and take up literature arguing that investors' 
preferences and beliefs vary with financial market cycles. By linking changes in retail investors' preferences and beliefs to changes in investors' selling behavior across financial market cycles, we highlight the importance of both proposed drivers of the disposition effect. 


\section{References}

Amromin, G./Sharpe, S. A., 2014, From the Horse's Mouth: Economic Conditions and Investor Expectations of Risk and Return, Management Science 60, 845 - 66.

An, L./Engelberg, J./Henriksson, M./Wang, B./Williams, J., The Portfolio-Driven Disposition Effect (May 25, 2019). Available at SSRN: https://ssrn.com/abstract=3126997 or http://dx.doi.org/10.2139/ssrn.3126997

Barber, B. M./Lee, Y./Liu, Y. Odean, T., 2007, Is the Aggregate Investor Reluctant to Realize Losses? Evidence from Taiwan, European Financial Management 13, 423 - 447.

Barber, B. M./Odean, T., 2000, Trading Is Hazardous to Your Wealth: The Common Stock Investment Performance of Individual Investors, The Journal of Finance 55, 773-806.

Barber, B. M./Odean, T., 2013, The Behavior of Individual Investors, Handbook of the Economics of Finance, Elsevier, Amsterdam, pp. 1533 - 1570.

Barberis, N., 2012, A Model of Casino Gambling, Management Science 58, 35 - 51.

Ben-David, I./Hirshleifer, D., 2012, Are Investors Really Reluctant to Realize Their Losses? Trading Responses to Past Returns and the Disposition Effect, Review of Financial Studies 25, $2485-2532$.

Birru, J., 2015, Confusion of Confusion: A Test of the Disposition Effect and Momentum, Review of Financial Studies 28, $1849-1873$.

Boolell-Gunesh, S./Broihann, M. H./Merli, M., 2009, Disposition effect, investor sophistication and taxes: Some French Specificities, Finance, Presses univ. de Grenoble, Grenoble, 51 - 87. Brown P./ Chappel, N./ da Silva Rosa R./Walter, T., 2006, The reach of the disposition effect: Large sample evidence across investor classes, International Review of Finance, 6(1-2), 43-78. Calvet, L. E./Campbell, J. Y./Sodini P., 2009, Fight or Flight? Portfolio Rebalancing by Individual Investors, Quarterly Journal of Economics 124, 301 - 348.

Chang, C. H., 2008, The Impact of Behavioral Pitfalls on Investors' Decisions: The Disposition Effect in the Taiwanese Warrant Market, Social Behavior and Personality 36, 617 - 634. 
Chang, T. Y/Solomon, D. H./Westerfield M., 2016, Looking for Someone to Blame: Delegation, Cognitive Dissonance and the Disposition Effect, The Journal of Finance 71, 267 - 302.

Chen, F./Figlewskiz, S./Heisler, J./Weigend, A. S., 1998, Uncovering Hidden Structure in Bond Futures Trading, Leonard N. Stern School of Business, New York University, Working Paper, 98-01, March 1998.

Choe, H./Eom, Y., 2009, The disposition effect and investment performance in futures market, Journal of Futures Markets 29, $496-522$.

Chui, M. W., 2001, An Experimental Study of the Disposition Effect: Evidence From Macau, Journal of Psychology and Financial Markets 2, 215-21.

Cici, G., 2012, The Prevalence of the Disposition Effect in Mutual Funds' Trades, Journal of Financial and Quantitative Analysis 47, 795 - 820.

Cohn, A./Engelmann, J./Fehr, E./Maréchal, M. A., 2015, Evidence for Countercyclical Risk Aversion: An Experiment with Financial Professionals, American Economic Review 105, 860 885.

Coval, J. D./Moskowitz, T. J., 1999, Home bias at home: Local equity preference in domestic portfolios, The Journal of Finance 54, 2045 - 2073.

Daniel, K./Moskowitz, T. J., 2016, Momentum crashes, Journal of Financial Economics 122, $221-247$.

Dhar, R./Zhu, N., 2006, Up Close and Personal: Investor Sophistication and the Disposition Effect, Management Science 52, 726-740.

Dominitz, J./Manski, C. F., 2011, Measuring and interpreting expectations of equity returns, Journal of applied econometrics 26, $352-370$.

Dorn, D,/Huberman, G./Sengmueller, P., 2008, Correlated Trading and Returns, The Journal of Finance 63, $885-920$.

Dorn, D./Strobl, G., 2009, Rational disposition effects: Theory and evidence, Drexel University, Working Paper. 
Eil, D./Rao, J. M., 2011, The Good News-Bad News Effect: SAsymmetric Processing of Objective Information about Yourself, American Economic Journal: Microeconomics 3, pp. 114 $-138$.

Feng, L./Seasholes, M. S., 2005, Do Investor Sophistication and Trading Experience Eliminate Behavioral Biases in Financial Markets?, Review of Finance 9, $305-351$.

Frazzini, A., 2006, The Disposition Effect and Underreaction to News, The Journal of Finance $61,2017-2046$.

Garvey, R./Murphy, A., 2004, Are Professional Traders too Slow to Realize their Losses?, Financial Analysts Journal 60, $35-43$.

Genesove, D./Mayer, C., 2001, Loss Aversion and Seller Behavior: Evidence from the Housing Market, National Bureau of Economic Research (NBER), Working Paper, 8143, March 2001.

Guiso, L./Sapienza, P./ Zingales, L., 2018, Time varying risk aversion, Journal of Financial Economics 128, $403-421$.

Greenwood, R./Shleifer, A., 2014, Expectations of Returns and Expected Returns, Review of Financial Studies 27, $714-746$.

Grinblatt, M./Keloharju M., 2001, What Makes Investors Trade?, The Journal of Finance 56, $589-616$.

Ivković, Z./Sialm, C./Weisbenner, S., 2008, Portfolio Concentration and the Performance of Individual Investors, Journal of Financial and Quantitative Analysis 43, 613 - 655.

Hartzmark, S. M./Solomon, D. H., 2012, Efficiency and the Disposition Effect in NFL Prediction Markets, The Quarterly Journal of Finance 2, 1-42.

Heath, C./Huddart, S./Lang, M., 1999, Psychological Factors and Stock Options Exercises, The Quarterly Journal of Finance 114, $601-627$.

Heisler, J., 1994, Loss Aversion in a Futures Market: An Empirical Analysis, The Review of Futures Markets 13, $793-822$.

Ingersoll J.E./Jin, L.J., 2013, Realization Utility and Reference-Dependent Preferences, Review of Financial Studies 26, 3, 723 - 767. 
Imas, A., 2016, The Realization Effect: Risk-Taking after Realized versus Paper Losses, American Economic Review 106, 2086 - 2019.

Kahneman, D./Tversky, A., 1979, Prospect Theory: An Analysis of Decision under Risk, Econometrica 47, 263-291.

Kaustia, M., 2010, Prospect Theory and the Disposition Effect, Journal of Financial and Quantitative Analysis 45, $791-812$.

Kaustia, M. 2004, Market-wide impact of the disposition effect: evidence from IPO trading volume, Journal of Financial Markets 7, $207-235$.

Kuhnen, C. A./Knutson, B., 2011, The Influence of Affect on Beliefs, Preferences and Financial Decisions, Journal of Financial and Quantitative Analysis 45, 605-626.

Kuhnen, C. M./Rudorf, S./Weber, B., 2017, The Effect of Prior Choices on Expectations and Subsequent Portfolio Decisions. NBER Working Paper No. w23438.

Kumar, A., 2009, Hard-to-Value Stocks, Behavioral Biases, and Informed Trading, Journal of Financial and Quantitative Analysis 44, 1375 - 1401.

Laudenbach, C./Loos, B./Pirschel, J./Wohlfart, J., 2020, The Trading Response of Individual Investors to Local Bankruptcies. SAFE Working Paper No. 272.

Loewenstein, G. F./Weber, E. U. / Hsee, C. K. /Welch, N. Risk as Feelings, 2001, Risk as feelings, Psychological Bulletin 127, 267-286

Malmendier, U./Nagel, S., 2011, Depression Babies: Do macroeconomic experiences affect risk taking?, The Quarterly Journal of Economics 126, $373-416$.

Odean, T., 1998, Are Investors Reluctant to Realize Their Losses?, The Journal of Finance 53, $1775-1798$.

Schmittmann, J. M./Pirschel, J./Meyer, S./Hackethal, A., 2015, The Impact of Weather on German Retail Investors, Review of Finance 19, 1143-1183.

Shapira, Z./Venezia, I., 2001, Patterns of behavior of professionally managed and independent investors, Journal of Banking and Finance 25, 1573 - 1587.

Shefrin, H./Statman, M., 1985, The Disposition to Sell Winners Too Early and Ride Losers Too Long: Theory and Evidence, The Journal of Finance 40, 777 - 790. 
Vissing-Jorgensen, A., 2003, Perspectives on behavioral finance: does "irrationality" disappear with wealth? Evidence from expectations and actions, NBER Macroeconomics Annual 2003, Volume 18, Mark Gertler and Kenneth Rogoff, MIT Press, Cambridge, MA, 189 - 297.

Tversky, A./ Kahneman, D., 1992, Advances in Prospect Theory: Cumulative Representation of Uncertainty, Journal of Risk and Uncertainty 5, 297 - 323.

Weber, M./Camerer, C.F., 1998, The disposition effect in securities trading: an experimental analysis, Journal of Economic Behavior \& Organization 33, 167 - 184.

Weber, M./Weber, E. U./Nosic, A., 2013, Who takes risks when and why: Determinates of changes in investor risk taking, Review of Finance 17, 847 - 883.

Wermers, R., 2003, Is Money Really 'Smart'? New Evidence on the Relation Between Mutual Fund Flows, Manager Behavior, and Performance Persistence, Working Paper, University of Maryland.

Wu, G./Gonzalez, R., 1996, Curvature of the probability weighting function. Management Science 42, 1676 - 1690. 


\section{Figures}

\section{Figure 1: The Disposition effect across boom and bust periods}

This figure depicts the evolution of the disposition effect (blue line) from January 2001 to December 2015 over a sample of almost 100,000 German investors. The disposition effect is calculated on a monthly basis using a rolling window approach over the last 12 months. Since our investor data set starts in 2001, the dashed blue line indicates calculations of the disposition effect based on less than 12 months of data. The gray shaded area represents a broad German market index (CDAX), which is indexed at 100 at the first trading day in 2001.

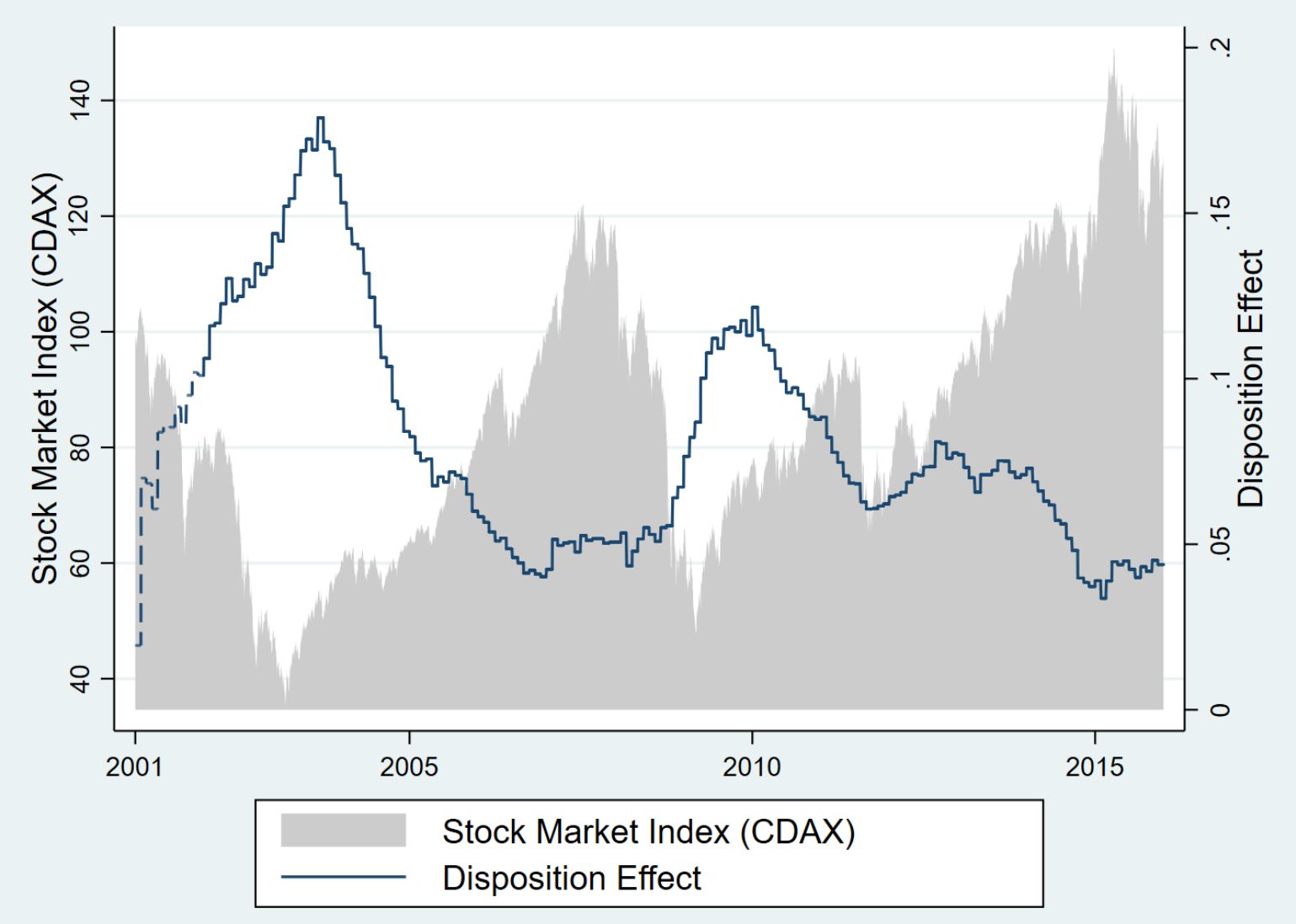




\section{Figure 2: Investor's decision problem as a function of return}

This figure shows investor's decision problem, i.e. the value of selling less the value of holding, that is, v(realized gain or loss) $-v$ (prospect), as a function of the gain or loss from the reference level. We use an exemplary asset that has an expected return of $12 \%$ and a volatility of $25 \%$ (as in Kaustia, 2010). The PT value function parameters are: $\beta=0.88, \lambda=2.25$. The dashed ( $\alpha=0.88$, boom investor) and solid line ( $\alpha=0.5$, bust investor) differ in the coefficient of risk aversion and illustrate changes in the investor's decision problem when risk aversion changes.

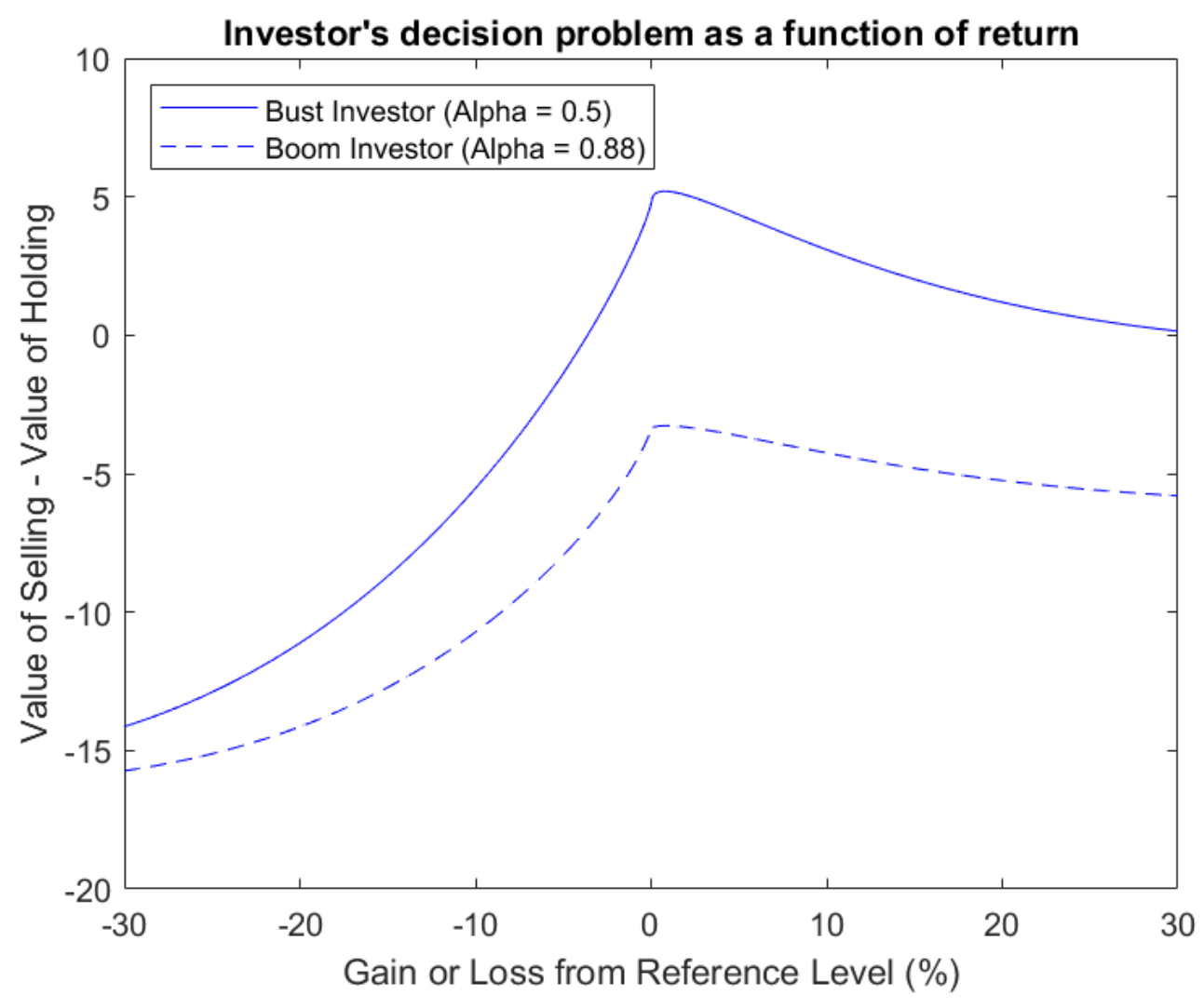


Figure 3: Empirical PGR and PLR in boom and bust cycles over return intervals

This figure shows the variation in the probability to sell, i.e. PGR and PLR, in boom and bust cycles as a function of the gain or loss from the reference level. The figure is based on regression results from Appendix $E$. The dashed line depicts investors' selling behavior in boom periods, whereas, the solid line depicts investors' selling behavior in bust periods.

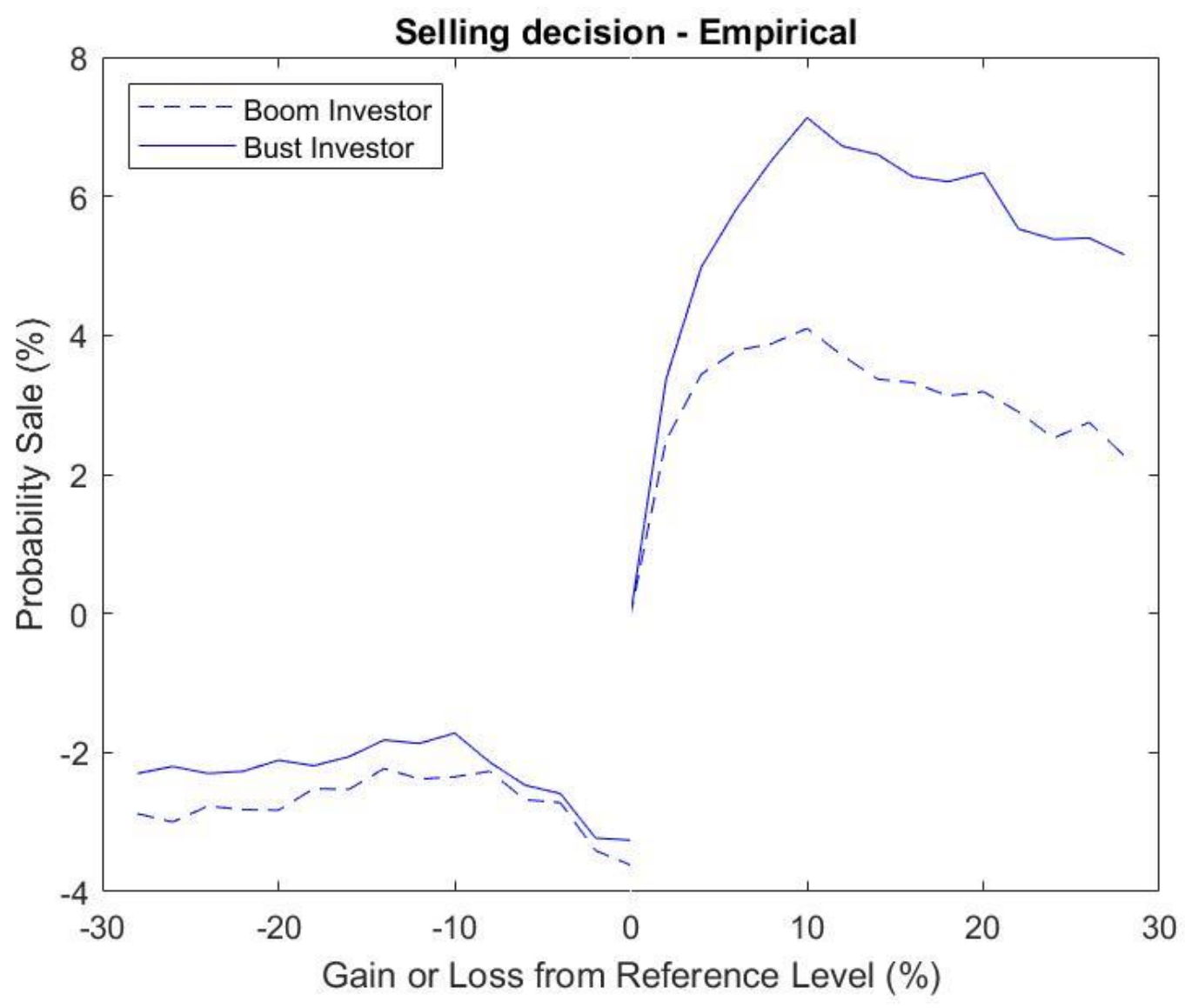




\section{Figure 4: PGR and PLR in boom and bust markets}

This figure shows the propensity to sell a stock at a gain (PGR) and the propensity to sell a stock at a loss (PLR) over time. Booms and busts are subdivided into deciles (X-axis) to account for differences in length across cycles. Observations at the beginning of a boom (bust) period are part of decile 1 , whereas observations at the end of a boom (bust) period are part of decile 10. PGR and PLR are calculated as in regression equation (2).

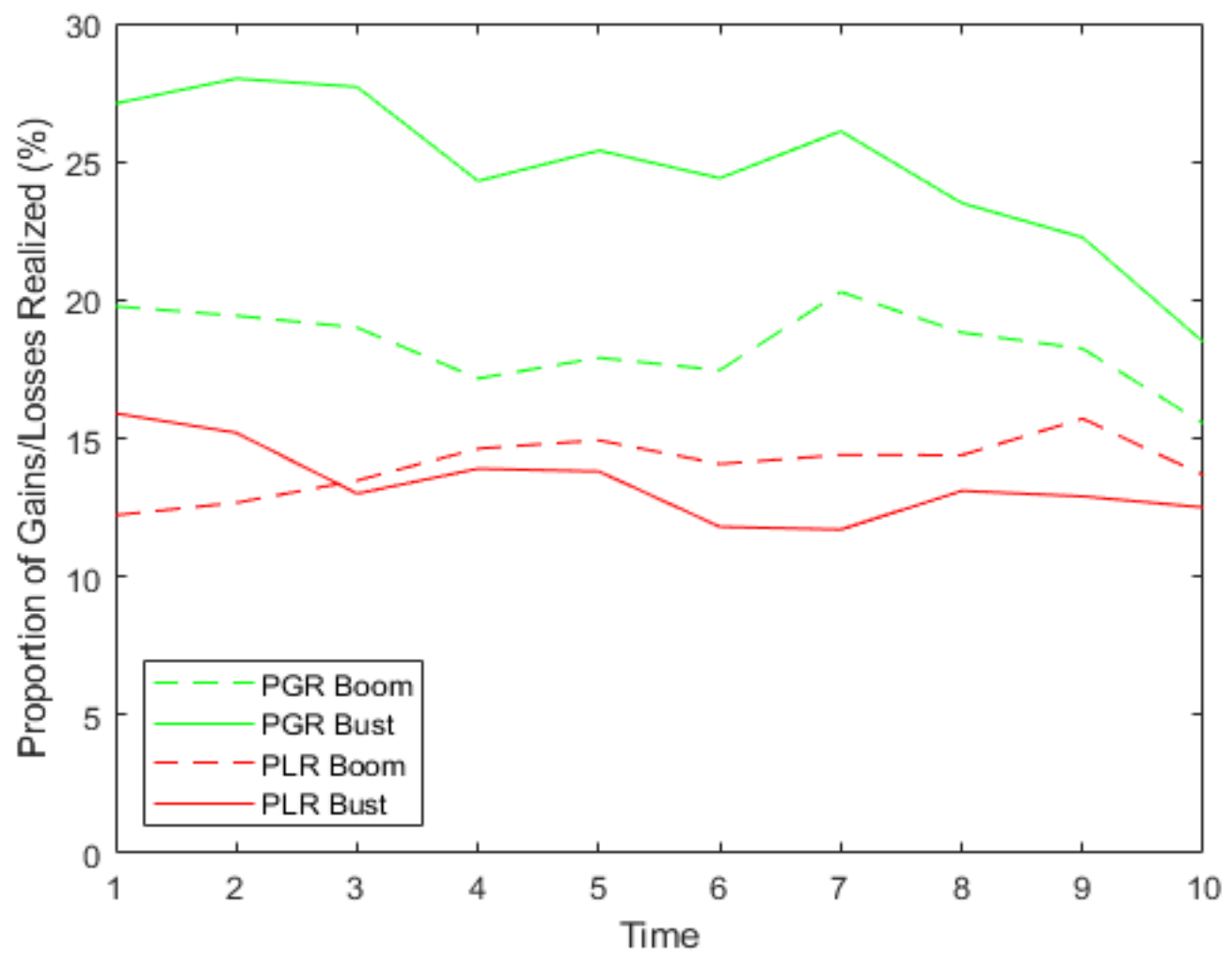




\section{Tables}

\section{Table 1: Summary statistics in boom and bust periods}

This table shows summary statistics for the filtered data used throughout this study, given that at least one sale took place in a given month. The sample is split into Boom and Bust markets based on the boom-bust definition by Daniel and Moskowitz (2016). Investors is the number of distinct investors that were active in the boom and/or bust period. Observations records the investor-stock-month triples. On the Investor Portfolio Level, the Average number of trades, the Average number of stocks held, Portfolio holdings at a gain, Portfolio holdings at a loss, the Average positive/negative stock return and the Herfindahl-Hirschman index (HHI) of an investor's portfolio are reported as monthly average. The $\mathrm{HHI}$ is calculated following Dorn et al. (2008). We report Age, Gender, and Education on the investor level. Test statistics (in parentheses) on the Investor Portfolio Level are calculated using standard errors that are two-way clustered on the investor and month level, whereas standard errors on the Investor Level are one-way clustered on the investor level. *, **, and $* * *$ indicate statistical significance at the $10 \%, 5 \%$, and $1 \%$ levels, respectively.

\begin{tabular}{lrrr}
\hline & Boom & Bust & $\begin{array}{r}\text { Difference in means } \\
\text { (Test statistic) }\end{array}$ \\
\hline Sample Split & & & \\
$\quad$ Investors & 80,860 & 69,439 & \\
$\quad$ Observations & $11,633,923$ & $6,646,570$ & \\
\hline Investor Portfolio Level & & & \\
$\quad$ Average number of trades (monthly) & 3.82 & 4.01 & $* *(-2.38)$ \\
$\quad$ Average Number stocks held (monthly) & 10 & 9.97 & $(0.38)$ \\
Herfindahl-Hirschman Index (HHI) & 35.04 & 39.25 & $(-1.42)$ \\
Average Stocks trading at a gain (\%) & 40.73 & 28.69 & $* * *(8.87)$ \\
Average Stocks trading at a loss (\%) & 59.27 & 71.31 & $* * *(-8.87)$ \\
Return gain - realized (\%) & 41.09 & 33.36 & $* * *(-6.47)$ \\
Return loss - realized (\%) & -36.05 & -43.97 & $* * *(8.94)$ \\
Return gain - paper (\%) & 37.57 & 29.75 & $* * *(8.25)$ \\
Return loss - paper (\%) & -38.31 & -46.69 & $* * *(11.85)$ \\
\hline Investor Level & & & \\
Age (Year) & 52.6 & 53.6 & $* * *(-14.10)$ \\
$\quad$ Gender (\%) & & & $* * *(-4.20)$ \\
$\quad$ Male & 86 & 87 & \\
$\quad$ Female & 14 & 13 & \\
Education (\%) & & & -0.12 \\
$\quad$ No title & & & \\
$\quad$ PhD or Professor & 94 & 94 & \\
\hline
\end{tabular}




\section{Table 2}

\section{Table 2a: The disposition effect across market cycles - Regression results}

This table examines the variation in the disposition effect between financial market cycles, i.e. boom and bust periods. We report the results of various regressions on the sample of $18,280,493$ investor-stock-month triples of individual investors from a German bank. Observations are taken monthly in months when at least one asset was sold in an investor's portfolio. The observation period ranges from January 2001 to December 2015. The dependent variable Sale is a dummy variable equal to one if the investor sells an asset within a particular month. Gain is a dummy variable equal to one if an asset's market price is above the reference point (here: defined as the value-weighted average purchase price). Boom is a dummy variable that equals one if the excess (of riskfree rate) cumulative CDAX return in the past 24 months is positive. Control variables are defined as in BenDavid and Hirshleifer (2012) (here BDH (2012)) and comprise the holding period, weighted-average purchase price, returns (positive and negative), and the interaction between holding periods and return. Standard errors (in parentheses) are two-way clustered by investor and month. ${ }^{*}, *$, and $* * *$ indicate statistical significance at the $10 \%, 5 \%$, and $1 \%$ levels, respectively.

(1)

(2)

(3)

(4)

Dependent Variable: Sale

Model 1

Model 2

Model 3

Model 4

Gain

$0.106 * * *$

$0.0973 * * *$

$0.109 * * *$

$0.121^{* * *}$

Boom

(0.00595)

(0.00529)

(0.00525)

(0.00647)

0.00184

$0.0131^{* * *}$

(0.00408)

$(0.00322)$

Gain $\times$ Boom

$-0.0518 * * *$

$-0.0417 * * *$

$-0.0483 * * *$

$-0.0527 * * *$

Constant

(0.00660)

(0.00587)

(0.00594)

(0.00617)

$0.133^{* * *}$

(0.00340)

Observations

$18,280,493$

$18,277,565$

$18,101,717$

$18,101,717$

R-squared

0.009

0.092

0.232

0.234

Cluster investor-month

YES

YES

YES

YES

Investor FE

YES

YES

YES

Month FE

YES

YES

Investor $\times$ Month FE

YES

YES

Controls as in BDH (2012)

YES

\section{Table $2 \mathrm{~b}$ : The disposition effect - Summary of regression results}

This table depicts the probabilities of selling a gain (loss) in boom and bust periods as estimated in regression equation (2). Numbers in this table are selling probabilities from Table 2a (column 1). Statistical significance of investors' selling behavior for gains (losses) across boom and bust markets are stated in column 4 of the matrix. Statistical Significance of investors' selling behavior for gains and losses within a boom (bust) period are stated in row $5 . *, * *$, and $* * *$ indicate statistical significance at the $10 \%, 5 \%$, and $1 \%$ levels, respectively.

\begin{tabular}{c|cc|c}
\hline & Boom & Bust & Significance \\
\hline Gain & $18.90 \%$ & $23.90 \%$ & $* * *$ \\
Loss & $13.48 \%$ & $13.30 \%$ & $* * *$ \\
\hline Disposition Effect & $5.42 \%$ & $10.60 \%$ & \\
\hline Significance & $* * *$ & $* * *$ & \\
\hline
\end{tabular}




\section{Table 3: The disposition effect over the entire time period}

This table examines the average disposition effect over the entire sample period (2001-2015). We report the results of various regressions on the sample of 18,280,493 investor-stock-month triples of individual investors from a German bank. Observations are taken monthly in months when at least one asset was sold in an investor's portfolio. The fixed date is the last trading day in each month. The dependent variable Sale is a dummy variable equal to one if the investor sells an asset within a particular month. Gain is a dummy variable equal to one if an asset's market price is above the reference point (here: defined as the value-weighted average purchase price). Standard errors (in parentheses) are two-way clustered by investor and month. * $* *$, and $* * *$ indicate statistical significance at the $10 \%, 5 \%$, and $1 \%$ levels, respectively.

\begin{tabular}{lcccc}
\hline Dependent Variable: Sale & $\begin{array}{c}(1) \\
\text { Model 1 }\end{array}$ & $\begin{array}{c}(2) \\
\text { Model 2 }\end{array}$ & $\begin{array}{c}(3) \\
\text { Model 3 }\end{array}$ & $\begin{array}{c}\text { (4) } \\
\text { Model 4 }\end{array}$ \\
\hline \multirow{2}{*}{ Gain } & & & & \\
& $0.0683^{* * *}$ & $0.0690^{* * *}$ & $0.0738^{* * *}$ & $0.0714^{* * *}$ \\
Constant & $(0.00340)$ & $(0.00324)$ & $(0.00350)$ & $(0.00318)$ \\
& $0.135^{* * *}$ & & & \\
Observations & $(0.00223)$ & & & \\
R-squared & & & & \\
Cluster investor-month & $18,280,493$ & $18,277,565$ & $18,280,493$ & $18,277,565$ \\
Investor FE & 0.008 & 0.092 & 0.012 & 0.094 \\
Month FE & YES & YES & YES & YES \\
\hline
\end{tabular}




\section{Table 4}

\section{Table 4a: Timing of sales- Regression results}

This table examines the effect of time on investors' selling pattern in boom and bust markets. We report the results of various regressions for Panel A (Gains) and Panel B (Losses), i.e. Panel A contains all assets trading at a gain, while Panel B contains all assets trading at a loss. Sale, Gain, and Boom are defined as in regression (1) to (2). Early (Advanced) is a dummy variable that equals one if the observation belongs to the first (last) three months of a boom or bust period. Intermediate is a dummy variable that is equal to one whenever an observation is not part of the Early or Advanced state. Standard errors (in parentheses) are two-way clustered by investor and month. ${ }^{*}, *$, and $* * *$ indicate statistical significance at the $10 \%, 5 \%$, and $1 \%$ levels, respectively.

Dependent Variable: Sale

Gain

Boom

Intermediate

Advanced

Gain $\times$ Boom

Gain $\times$ Intermediate

Gain $\times$ Advanced

Boom $\times$ Intermediate

Boom $\times$ Advanced

Gain $\times$ Boom $\times$ Intermediate

Gain $\times$ Boom $\times$ Advanced

Constant

Observations

R-squared

Cluster investor-month

Investor FE

Number of Assets in PF
(1)

Model 1

(2)

Model 2

$0.0920 * * *$

$0.110 * * *$

(0.0245)

(0.0237)

$-0.0220 * *$

$-0.0318^{* * *}$

(0.0101)

$-0.0176^{*}$

$-0.0163$

(0.00909)

(0.0104)

$-0.0317^{* * *}$

$-0.0192 *$

(0.0119)

(0.0113)

$-0.0311$

$-0.0155$

(0.0245)

(0.0254)

0.00340

0.0124

(0.0246)

(0.0251)

$-0.0441^{*}$

$-0.0248$

(0.0264)

(0.0268)

$0.0351 * * *$

$0.0376 * * *$

(0.00935)

(0.0107)

$0.0363 * * *$

$0.0380 * * *$

(0.0120)

(0.0119)

$-0.0299$

$-0.0335$

(0.0256)

(0.0262)

0.000327

$-0.0130$

(0.0288)

(0.0290)

$0.169 * * *$

(0.00881)

$17,723,068$
0.019
YES

$17,720,100$

0.093

YES

YES 
Table 4b: Timing of sales - Summary of regression results

This table depicts the probabilities of selling a gain (loss) in boom and bust periods as estimated in the regression equation (5). Numbers in this table are selling probabilities from Table 4a (column 1). Differences in selling a gain (loss) across boom and bust markets are stated by the test statistic in column 4 of each matrix.

\begin{tabular}{llll}
\hline Gain & Boom & Bust & Significance \\
\hline Early & $21.61 \%$ & $27.90 \%$ & $* * *$ \\
Intermediate & $20.71 \%$ & $26.48 \%$ & $* * *$ \\
Advanced & $17.69 \%$ & $20.32 \%$ & $* *$ \\
\hline & & & \\
\hline Loss & Boom & Bust & Significance \\
\hline Early & $13.72 \%$ & $16.90 \%$ & $* * *$ \\
Intermediate & $15.47 \%$ & $15.14 \%$ & \\
Advanced & $14.18 \%$ & $13.73 \%$ & \\
\hline
\end{tabular}




\section{Table 5: The portfolio driven disposition effect}

This table examines the variation in the disposition effect between financial market cycles, i.e. boom and bust periods while controlling for the portfolio driven disposition effect. The main difference to previous tables is that: Panel A comprises the sample of investors who hold a portfolio with an overall positive portfolio value in boom periods. Panel B comprises the sample of investors who hold a portfolio with an overall positive portfolio value in bust periods. Standard errors (in parentheses) are two-way clustered by investor and month. ${ }^{*}, * *$, and $* * *$ indicate statistical significance at the $10 \%, 5 \%$, and $1 \%$ levels, respectively.

\section{Panel A: Overall positive portfolio value in boom period}

\section{Dependent Variable: Sale}

Gain

Constant

Observations

R-squared

Cluster investor-month

Investor FE

Month FE
(1)

(2) Model 1

0.00241

(0.00413)

$0.164 * * *$

(0.00462) Model 2

$-0.00123$

0.00488

(0.00413)

(0.00395)
(3)

(4)

Model 3
0.00378

Model 4

$(0.00397)$

Panel B: Overall positive portfolio value in bust period

(1)

(2)

(3)

(4)

Dependent Variable: Sale

Model 1

Model 2

Model 3

Model 4

Gain

$0.0538 * * *$
$(0.00660)$
$0.159 * * *$

$0.0341 * * *$

$0.0513 * * *$

$0.0385^{* * *}$

Constant

(0.00591)

Observations

R-squared

Cluster investor-month

Investor FE

Month FE

537,612
0.005
YES

535,672
0.148
YES
YES

535,672

0.017

0.151

YES

YES

YES

YES YES 


\section{Table 6: Various boom and bust definitions}

This table examines the variation in the disposition effect between cycles, i.e. boom and bust periods using various different boom and bust definitions. Gain is a dummy variable equal to one if an asset's market price at is above the reference point (here: defined as the value-weighted average purchase price). Boom is a dummy variable that equals one if the market is in a boom period given the boom definition for the respective model. In Model 1 the boom dummy equals one if the excess cumulative CDAX return in the past 12 months is strictly greater than zero. In Model 2 the boom dummy equals one if the excess cumulative CDAX return (12 months lagged) falls into the top $30 \%$ of the market return over the sample period. The boom dummy is zero if the excess cumulative CDAX return ( 12 months lagged) falls into the bottom $30 \%$ of the market return. If the return falls neither into the top nor bottom 30\% the Neutral dummy equals one. In Model 3 the boom dummy equals one (zero) if the excess cumulative CDAX return over the past 12 months is greater than (small or equal to) zero for at least three months in a row. Finally, Model 4 uses the NBER bust period definition. The boom dummy is equal to zero if the German GDP decreases in two consecutive quarters. Standard errors (in parentheses) are two-way clustered by investor and month. ${ }^{*}, *$, and $* * *$ indicate statistical significance at the $10 \%, 5 \%$, and $1 \%$ levels, respectively.

\begin{tabular}{lcccc}
\hline Dependent Variable: Sale & $(1)$ & $(2)$ & $(3)$ & $(4)$ \\
Goin & & Model 2 & Model 3 & Model 4 \\
\hline Boom & $0.108^{* * *}$ & $0.120^{* * *}$ & $0.111^{* * *}$ & $0.0891^{* * *}$ \\
& $(0.00724)$ & $(0.00826)$ & $(0.00753)$ & $(0.0129)$ \\
Neutral & 0.00178 & 0.00261 & 0.00224 & $0.0112^{*}$ \\
& $(0.00427)$ & $(0.00515)$ & $(0.00446)$ & $(0.00585)$ \\
Gain $\times$ Boom & & $-0.00885^{*}$ & $-0.0170^{* * *}$ & \\
& & $(0.00496)$ & $(0.00574)$ & \\
Gain $\times$ Neutral & $-0.0504^{* * *}$ & $-0.0633^{* * *}$ & $-0.0554^{* * *}$ & $-\mathbf{0 . 0 2 2 2 *}$ \\
& $(0.00780)$ & $(0.00903)$ & $(0.00806)$ & $(0.0132)$ \\
Constant & & $-0.0576^{* * *}$ & -0.0160 & \\
& & $(0.00936)$ & $(0.0136)$ & \\
Observations & $0.133^{* * *}$ & $0.137^{* * *}$ & $0.134^{* * *}$ & $0.124 * * *$ \\
R-squared & $(0.00375)$ & $(0.00416)$ & $(0.00392)$ & $(0.00562)$ \\
Cluster investor-month & & & & \\
\hline
\end{tabular}




\section{Appendix}

\section{Appendix A: Literature on the disposition effect}

\section{Panel 1:}

This table lists prominent papers on the disposition effect among different investor types, in various asset classes, and across geographical regions.

\begin{tabular}{ll}
\hline The disposition effect among & different investors types \\
\hline Retail investors & Odean (1998), Kumar (2009), Feng and Seasholes (2005), \\
& Dhar and Zhu (2006) \\
Institutional investors & Wermers (2003), Frazzini (2006), Garvey and Murphy \\
& (2004), Cici (2012) \\
\hline The disposition effect in various asset classes \\
\hline Stocks & Odean (1998) \\
Executive stock options & Heath et al. (1999) \\
Stock index futures & Heisler (1994), Chen et al. (1998), Choe and Eom (2009) \\
Warrants & Chang (2008) \\
Online betting & Hartzmark and Solomon (2012) \\
Housing & Genesove and Mayer (2001) \\
\hline The disposition effect across geographical regions \\
\hline USA & Odean (1998), Frazzini (2006), Cici (2012) \\
Europe & Grinblatt and Keloharju (2001), Boolell-Gunesh et al. \\
& (2009), Calvet et al. (2009), Weber and Camerer (1998), \\
& Dorn and Strobl (2009) \\
Asia & Chui (2001), Feng and Seasholes (2005), Chang (2008), \\
& Barber et al. (2007) \\
Middle East & Shapira and Venezia (2001) \\
\hline
\end{tabular}

\section{Panel 2:}

This table lists prominent papers on the disposition effect and the sample period used in the paper. Corresponding to the country specific trading pattern analyzed in one paper, we calculate the average p.a. market return. The market index applied is indicated in column (3).

\begin{tabular}{lrrr}
\hline Articles & Sample Period & Market Index & $\begin{array}{r}\text { Arithmetic } \\
\text { average (p.a.) }\end{array}$ \\
\hline Odean (1998) & $1987-1993$ & S\&P 500 & $13.3 \%$ \\
Barber and Odean (2000) & $1991-1996$ & S\&P 500 & $21.8 \%$ \\
Grinblatt and Keloharju (2001) & $1995-2000$ & OMX Helsinki 25 & $39.0 \%$ \\
Feng and Seasholes (2005) & $1999-2000$ & SSE Composite Index & $42.5 \%$ \\
Brown et al. (2006) & $1995-2000$ & All Ordinaries & $8.0 \%$ \\
Dhar and Zu (2006) & $1991-1996$ & S\&P 500 & $21.8 \%$ \\
Weber and Welfens (2006) & $1997-2001$ & DAX 30 & $23.5 \%$ \\
Barber et al. (2007) & $1995-1999$ & TAIEX & $4.1 \%$ \\
Dorn and Strobl (2009) & $1995-2000$ & DAX 30 & $45.2 \%$ \\
Kaustia (2010) & $1995-2000$ & OMX Helsinki 25 & $39.0 \%$ \\
Chang et al. (2016) & $1991-1996$ & S\&P 500 & $21.8 \%$ \\
\hline
\end{tabular}




\section{Appendix B: Categorization of boom and bust months using various definitions}

This table shows the months that are categorized as Boom, Bust, or Neutral months using different boom and bust definitions. There are five different bust definitions: the main measure (Daniel and Moskowitz, 2016) and four alternative measures (Model 1, Model2, Model 3, Model 4). In Alternative model 1 the boom dummy equals one if the excess cumulative CDAX return in the past 12 months is strictly greater than zero. In Alternative model 2 the boom dummy equals one if the excess cumulative CDAX return (12 months lagged) falls into the top $30 \%$ of the market return over the sample period. The boom dummy is zero if the excess cumulative CDAX return (12 months lagged) falls into the bottom $30 \%$ of the market return. If the return falls neither into the top nor bottom $30 \%$ the Neutral dummy equals one. In Alternative model 3 the boom dummy equals one (zero) if the excess cumulative CDAX return over the past 12 months is greater than (small or equal to) zero for at least three months in a row. Alternative model 4 uses the NBER bust period definition, i.e. the boom dummy is equal to zero if the German GDP decreases in two consecutive quarters.

\begin{tabular}{|c|c|c|c|c|c|c|c|c|c|c|c|c|}
\hline & & & & & & & 2001 & & & & & \\
\hline & January & February & March & April & May & June & July & August & September & October & November & December \\
\hline Daniel and Moskowitz (2016) & Boom & Boom & Boom & Bust & Bust & Bust & Bust & Bust & Bust & Bust & Bust & Bust \\
\hline Alternative model 1 & Bust & Bust & Bust & Bust & Bust & Bust & Bust & Bust & Bust & Bust & Bust & Bust \\
\hline Alternative model 2 & Bust & Neutral & Bust & Bust & Bust & Bust & Bust & Bust & Bust & Bust & Bust & Bust \\
\hline Alternative model 3 & Neutral & Neutral & Bust & Bust & Bust & Bust & Bust & Bust & Bust & Bust & Bust & Bust \\
\hline \multirow[t]{3}{*}{ Alternative model 4 (NBER) } & Boom & Boom & Boom & Boom & Boom & Boom & Boom & Boom & Boom & Boom & Boom & Boom \\
\hline & & & & & & & 2002 & & & & & \\
\hline & January & February & March & April & May & June & July & August & September & October & November & December \\
\hline Daniel and Moskowitz (2016) & Bust & Bust & Bust & Bust & Bust & Bust & Bust & Bust & Bust & Bust & Bust & Bust \\
\hline Alternative model 1 & Bust & Bust & Bust & Bust & Bust & Bust & Bust & Bust & Bust & Bust & Bust & Bust \\
\hline Alternative model 2 & Bust & Bust & Bust & Neutral & Bust & Bust & Bust & Bust & Bust & Bust & Bust & Bust \\
\hline Alternative model 3 & Bust & Bust & Bust & Bust & Bust & Bust & Bust & Bust & Bust & Bust & Bust & Bust \\
\hline \multirow[t]{3}{*}{ Alternative model 4 (NBER) } & Boom & Boom & Boom & Boom & Boom & Boom & Boom & Boom & Boom & Boom & Boom & Boom \\
\hline & & & & & & & 2003 & & & & & \\
\hline & January & February & March & April & May & June & July & August & September & October & November & December \\
\hline Daniel and Moskowitz (2016) & Bust & Bust & Bust & Bust & Bust & Bust & Bust & Bust & Bust & Bust & Bust & Bust \\
\hline Alternative model 1 & Bust & Bust & Bust & Bust & Bust & Bust & Bust & Bust & Bust & Boom & Boom & Boom \\
\hline Alternative model 2 & Bust & Bust & Bust & Bust & Bust & Bust & Bust & Bust & Bust & Neutral & Neutral & Neutral \\
\hline Alternative model 3 & Bust & Bust & Bust & Bust & Bust & Bust & Bust & Bust & Bust & Neutral & Neutral & Boom \\
\hline \multirow[t]{3}{*}{ Alternative model 4 (NBER) } & Bust & Bust & Bust & Boom & Boom & Boom & Boom & Boom & Boom & Boom & Boom & Boom \\
\hline & & & & & & & 2004 & & & & & \\
\hline & January & February & March & April & May & June & July & August & September & October & November & December \\
\hline Daniel and Moskowitz (2016) & Bust & Bust & Bust & Bust & Bust & Bust & Bust & Bust & Bust & Boom & Boom & Boom \\
\hline Alternative model 1 & Boom & Boom & Boom & Boom & Boom & Boom & Boom & Boom & Boom & Boom & Boom & Boom \\
\hline Alternative model 2 & Boom & Boom & Boom & Boom & Boom & Boom & Boom & Neutral & Neutral & Neutral & Neutral & Neutral \\
\hline Alternative model 3 & Boom & Boom & Boom & Boom & Boom & Boom & Boom & Boom & Boom & Boom & Boom & Boom \\
\hline \multirow[t]{3}{*}{ Alternative model 4 (NBER) } & Boom & Boom & Boom & Boom & Boom & Boom & Boom & Boom & Boom & Boom & Boom & Boom \\
\hline & & & & & & & 2005 & & & & & \\
\hline & January & February & March & April & May & June & July & August & September & October & November & December \\
\hline Daniel and Moskowitz (2016) & Boom & Boom & Boom & Boom & Boom & Boom & Boom & Boom & Boom & Boom & Boom & Boom \\
\hline Alternative model 1 & Boom & Boom & Boom & Boom & Boom & Boom & Boom & Boom & Boom & Boom & Boom & Boom \\
\hline Alternative model 2 & Neutral & Neutral & Neutral & Neutral & Neutral & Neutral & Neutral & Boom & Boom & Boom & Boom & Boom \\
\hline Alternative model 3 & Boom & Boom & Boom & Boom & Boom & Boom & Boom & Boom & Boom & Boom & Boom & Boom \\
\hline Alternative model 4 (NBER) & Boom & Boom & Boom & Boom & Boom & Boom & Boom & Boom & Boom & Boom & Boom & Boom \\
\hline
\end{tabular}




\begin{tabular}{|c|c|c|c|c|c|c|c|c|c|c|c|c|}
\hline & & & & & & & 2006 & & & & & \\
\hline & January & February & March & April & May & June & July & August & September & October & November & December \\
\hline Daniel and Moskowitz (2016) & Boom & Boom & Boom & Boom & Boom & Boom & Boom & Boom & Boom & Boom & Boom & Boom \\
\hline Alternative model 1 & Boom & Boom & Boom & Boom & Boom & Boom & Boom & Boom & Boom & Boom & Boom & Boom \\
\hline Alternative model 2 & Boom & Boom & Boom & Boom & Boom & Boom & Boom & Neutral & Neutral & Neutral & Boom & Neutral \\
\hline Alternative model 3 & Boom & Boom & Boom & Boom & Boom & Boom & Boom & Boom & Boom & Boom & Boom & Boom \\
\hline \multirow[t]{3}{*}{ Alternative model 4 (NBER) } & Boom & Boom & Boom & Boom & Boom & Boom & Boom & Boom & Boom & Boom & Boom & Boom \\
\hline & & & & & & & 2007 & & & & & \\
\hline & January & February & March & April & May & June & July & August & September & October & November & December \\
\hline Daniel and Moskowitz (2016) & Boom & Boom & Boom & Boom & Boom & Boom & Boom & Boom & Boom & Boom & Boom & Boom \\
\hline Alternative model 1 & Boom & Boom & Boom & Boom & Boom & Boom & Boom & Boom & Boom & Boom & Boom & Boom \\
\hline Alternative model 2 & Boom & Neutral & Neutral & Neutral & Boom & Boom & Boom & Boom & Boom & Boom & Boom & Neutral \\
\hline Alternative model 3 & Boom & Boom & Boom & Boom & Boom & Boom & Boom & Boom & Boom & Boom & Boom & Boom \\
\hline \multirow[t]{3}{*}{ Alternative model 4 (NBER) } & Boom & Boom & Boom & Boom & Boom & Boom & Boom & Boom & Boom & Boom & Boom & Boom \\
\hline & & & & & & & 2008 & & & & & \\
\hline & January & February & March & April & May & June & July & August & September & October & November & December \\
\hline Daniel and Moskowitz (2016) & Boom & Boom & Boom & Bust & Boom & Boom & Boom & Boom & Bust & Bust & Bust & Bust \\
\hline Alternative model 1 & Boom & Bust & Bust & Bust & Bust & Bust & Bust & Bust & Bust & Bust & Bust & Bust \\
\hline Alternative model 2 & Neutral & Neutral & Neutral & Neutral & Bust & Bust & Bust & Bust & Bust & Bust & Bust & Bust \\
\hline Alternative model 3 & Boom & Neutral & Neutral & Bust & Bust & Bust & Bust & Bust & Bust & Bust & Bust & Bust \\
\hline \multirow[t]{3}{*}{ Alternative model 4 (NBER) } & Boom & Boom & Boom & Boom & Boom & Boom & Bust & Bust & Bust & Bust & Bust & Bust \\
\hline & & & & & & & 2009 & & & & & \\
\hline & January & February & March & April & May & June & July & August & September & October & November & December \\
\hline Daniel and Moskowitz (2016) & Bust & Bust & Bust & Bust & Bust & Bust & Bust & Bust & Bust & Bust & Bust & Bust \\
\hline Alternative model 1 & Bust & Bust & Bust & Bust & Bust & Bust & Bust & Bust & Bust & Bust & Bust & Boom \\
\hline Alternative model 2 & Bust & Bust & Bust & Bust & Bust & Bust & Bust & Bust & Bust & Bust & Neutral & Neutral \\
\hline Alternative model 3 & Bust & Bust & Bust & Bust & Bust & Bust & Bust & Bust & Bust & Bust & Bust & Neutral \\
\hline \multirow[t]{3}{*}{ Alternative model 4 (NBER) } & Bust & Bust & Bust & Boom & Boom & Boom & Boom & Boom & Boom & Boom & Boom & Boom \\
\hline & & & & & & & 2010 & & & & & \\
\hline & January & February & March & April & May & June & July & August & September & October & November & December \\
\hline Daniel and Moskowitz (2016) & Bust & Bust & Bust & Bust & Bust & Bust & Bust & Bust & Bust & Bust & Boom & Boom \\
\hline Alternative model 1 & Boom & Boom & Boom & Boom & Boom & Boom & Boom & Boom & Boom & Boom & Boom & Boom \\
\hline Alternative model 2 & Neutral & Boom & Boom & Boom & Boom & Neutral & Boom & Neutral & Neutral & Neutral & Neutral & Neutral \\
\hline Alternative model 3 & Neutral & Boom & Boom & Boom & Boom & Boom & Boom & Boom & Boom & Boom & Boom & Boom \\
\hline \multirow[t]{3}{*}{ Alternative model 4 (NBER) } & Boom & Boom & Boom & Boom & Boom & Boom & Boom & Boom & Boom & Boom & Boom & Boom \\
\hline & & & & & & & 2011 & & & & & \\
\hline & January & February & March & April & May & June & July & August & September & October & November & December \\
\hline Daniel and Moskowitz (2016) & Boom & Boom & Boom & Boom & Boom & Boom & Boom & Boom & Boom & Bust & Boom & Boom \\
\hline Alternative model 1 & Boom & Boom & Boom & Boom & Boom & Boom & Boom & Boom & Bust & Bust & Bust & Bust \\
\hline Alternative model 2 & Neutral & Boom & Boom & Neutral & Boom & Boom & Boom & Neutral & Neutral & Bust & Neutral & Neutral \\
\hline Alternative model 3 & Boom & Boom & Boom & Boom & Boom & Boom & Boom & Boom & Neutral & Neutral & Bust & Bust \\
\hline Alternative model 4 (NBER) & Boom & Boom & Boom & Boom & Boom & Boom & Boom & Boom & Boom & Boom & Boom & Boom \\
\hline
\end{tabular}




\begin{tabular}{|c|c|c|c|c|c|c|c|c|c|c|c|c|}
\hline & & & & & & & 2012 & & & & & \\
\hline & January & February & March & April & May & June & July & August & September & October & November & December \\
\hline Daniel and Moskowitz (2016) & Bust & Boom & Boom & Boom & Boom & Bust & Boom & Boom & Boom & Boom & Boom & Boom \\
\hline Alternative model 1 & Bust & Bust & Bust & Bust & Bust & Bust & Bust & Bust & Boom & Boom & Boom & Boom \\
\hline Alternative model 2 & Bust & Neutral & Neutral & Neutral & Bust & Bust & Bust & Neutral & Neutral & Boom & Neutral & Boom \\
\hline Alternative model 3 & Bust & Bust & Bust & Bust & Bust & Bust & Bust & Bust & Neutral & Neutral & Boom & Boom \\
\hline \multirow[t]{3}{*}{ Alternative model 4 (NBER) } & Boom & Boom & Boom & Boom & Boom & Boom & Boom & Boom & Boom & Boom & Boom & Boom \\
\hline & & & & & & & 2013 & & & & & \\
\hline & January & February & March & April & May & June & July & August & September & October & November & December \\
\hline Daniel and Moskowitz (2016) & Boom & Boom & Bust & Boom & Bust & Boom & Boom & Boom & Boom & Boom & Boom & Boom \\
\hline Alternative model 1 & Boom & Boom & Boom & Boom & Boom & Boom & Boom & Boom & Boom & Boom & Boom & Boom \\
\hline Alternative model 2 & Boom & Boom & Neutral & Neutral & Neutral & Boom & Boom & Boom & Neutral & Boom & Boom & Boom \\
\hline Alternative model 3 & Boom & Boom & Boom & Boom & Boom & Boom & Boom & Boom & Boom & Boom & Boom & Boom \\
\hline \multirow[t]{3}{*}{ Alternative model 4 (NBER) } & Bust & Bust & Bust & Boom & Boom & Boom & Boom & Boom & Boom & Boom & Boom & Boom \\
\hline & & & & & & & 2014 & & & & & \\
\hline & January & February & March & April & May & June & July & August & September & October & November & December \\
\hline Daniel and Moskowitz (2016) & Boom & Boom & Boom & Boom & Boom & Boom & Boom & Boom & Boom & Boom & Boom & Boom \\
\hline Alternative model 1 & Boom & Boom & Boom & Boom & Boom & Boom & Boom & Boom & Boom & Boom & Boom & Boom \\
\hline Alternative model 2 & Boom & Boom & Boom & Boom & Boom & Neutral & Boom & Neutral & Neutral & Neutral & Neutral & Neutral \\
\hline Alternative model 3 & Boom & Boom & Boom & Boom & Boom & Boom & Boom & Boom & Boom & Boom & Boom & Boom \\
\hline \multirow[t]{3}{*}{ Alternative model 4 (NBER) } & Boom & Boom & Boom & Boom & Boom & Boom & Boom & Boom & Boom & Boom & Boom & Boom \\
\hline & & & & & & & 2015 & & & & & \\
\hline & January & February & March & April & May & June & July & August & September & October & November & December \\
\hline Daniel and Moskowitz (2016) & Boom & Boom & Boom & Boom & Boom & Boom & Boom & Boom & Boom & Boom & Boom & Boom \\
\hline Alternative model 1 & Boom & Boom & Boom & Boom & Boom & Boom & Boom & Boom & Boom & Boom & Boom & Boom \\
\hline Alternative model 2 & Neutral & Neutral & Neutral & Boom & Boom & Neutral & Neutral & Boom & Neutral & Neutral & Neutral & Neutral \\
\hline Alternative model 3 & Boom & Boom & Boom & Boom & Boom & Boom & Boom & Boom & Boom & Boom & Boom & Boom \\
\hline Alternative model 4 (NBER) & Boom & Boom & Boom & Boom & Boom & Boom & Boom & Boom & Boom & Boom & Boom & Boom \\
\hline
\end{tabular}




\section{Appendix C: MSCl ACWI as market measure}

This table examines the variation in the disposition effect between financial market cycles using the $\mathrm{MSCl} A C W I$ instead of the CDAX as the financial market index. We report the results of various regressions on the sample of $18,280,493$ investor-stock-month triples of individual investors from a German bank. Observations are taken monthly in months when at least one asset was sold in an investor's portfolio. The fixed date is the last trading day in each month. The observation period ranges from January 2001 to December 2015. The dependent variable Sale is a dummy variable equal to one if the investor sells an asset within a particular month. Gain is a dummy variable equal to one if an asset's market price is above the reference point (here: defined as the valueweighted average purchase price). Column (1) to (4) examines variation in the disposition effect using several boom/bust definitions. The boom definition at work is indicated by the column's title. For example, column's (1) title is "Table 2a (1)" meaning that the boom definition is identical to the boom definition used in Table 2a column (1), i.e. the Daniel and Moskowitz (2016) definition is at work. Standard errors (in parentheses) are twoway clustered by investor and month. $*, * *$, and $* * *$ indicate statistical significance at the $10 \%, 5 \%$, and $1 \%$ levels, respectively.

(1) (2) (3) (4)

\begin{tabular}{lcccc} 
Dependent Variable: Sale & Table 2a (1) & Table 6 (1) & Table 6 (2) & Table 6 (3) \\
\hline Gain & & & & \\
& $0.106^{* * *}$ & $0.110^{* * *}$ & $0.118^{* * *}$ & $0.115^{* * *}$ \\
Boom & $(0.00604)$ & $(0.00737)$ & $(0.00763)$ & $(0.00766)$ \\
& 0.00286 & -0.00192 & -0.00475 & -0.000543 \\
Neutral & $(0.00404)$ & $(0.00441)$ & $(0.00517)$ & $(0.00451)$ \\
& & & -0.00546 & -0.00588 \\
Gain $\times$ Boom & & & $(0.00508)$ & $(0.00877)$ \\
& $-0.0514^{* * *}$ & $-0.0516^{* * *}$ & $-0.0567^{* * *}$ & $-0.0597^{* * *}$ \\
Gain $\times$ Neutral & $(0.00671)$ & $(0.00791)$ & $(0.00867)$ & $(0.00817)$ \\
& & & $-0.0580 * * *$ & $-0.0254^{* *}$ \\
Constant & & & $(0.00883)$ & $(0.0127)$ \\
& $0.133^{* * *}$ & $0.136 * * *$ & $0.138^{* * *}$ & $0.135^{* * *}$ \\
& $(0.00333)$ & $(0.00396)$ & $(0.00419)$ & $(0.00400)$ \\
Observations & & & & \\
R-squared & $18,280,493$ & $18,280,493$ & $18,280,493$ & $18,280,493$ \\
Cluster investor-month & 0.009 & 0.009 & 0.009 & 0.010 \\
& YES & YES & YES & YES \\
\hline
\end{tabular}




\section{Appendix D: Change in the number of paper gains across market cycles}

This table replicates the results of our baseline regression (regression equation (2)) while controlling for the absolute number of paper gains. Regressors are defined as is regression equation (2). Results are reported for various regressions on the sample of $18,277,565$ investors. Standard errors (in parentheses) are two-way clustered by investor and month. ${ }^{*}, *$, and $* * *$ indicate statistical significance at the $10 \%, 5 \%$, and $1 \%$ levels, respectively.

(1) (2)

Gain

Boom

Gain $\times$ Boom

Observations

R-squared

Cluster investor-month

Investor FE

Number Gains
$0.121 * * *$
$0.129 * * *$
(0.00205)
(0.00839)
$-0.00506 * * *$
(0.00118)
$0.0124 * * *$
$-0.0540 * * *$
(0.00349)
(0.00231)
$-0.0557^{* * *}$
(0.00723)

$18,277,565$

0.092

$18,277,565$

YES

0.097

YES

YES

YES

YES 


\section{Appendix E: Empirical PGR and PLR in boom and bust cycles over return intervals}

This table examines the variation in the PGR and PLR across financial market cycles as a function of the gain or loss from the reference level. Therefore, the gain dummy variable of regression equation (2) is replaced by return interval dummy variables ranging from $-30 \%$ to $+30 \%$ return, in two percentage point increments. Returns smaller (bigger) than $-30 \%(+30 \%)$ are subsumed in the extreme $-30 \%(+30 \%)$ return interval. Return $[0,2)$ is subsumed in the constant. To avoid a large number of interaction terms we do not include a boom dummy variable but run the regression separately on the boom (column 1 and 2) and bust (column 3 and 4) sample. Boom and bust are defined based as in Daniela and Moskowitz (2016). Since we want to investigate investors' PGR and PLR in boom and bust periods over a wide range of returns, we restrict our sample to investors who hold a particular stock within a boom and a bust period. This shrinks the number of observations from our main sample by $35 \%$. Standard errors (in parentheses) are two-way clustered by investor and month. *, $* *$, and $* * *$ indicate statistical significance at the $10 \%, 5 \%$, and $1 \%$ levels, respectively.

\begin{tabular}{|c|c|c|c|c|}
\hline & \multicolumn{2}{|c|}{ Boom Sample } & \multicolumn{2}{|c|}{ Bust Sample } \\
\hline & (1) & (2) & (3) & (4) \\
\hline Dependent Variable: Sale & Gain & Loss & Gain & Loss \\
\hline Return $(0,2)$ & & $\begin{array}{c}-0.0362^{* * *} \\
(0.00204)\end{array}$ & & $\begin{array}{c}-0.0326 * * * \\
(0.00215)\end{array}$ \\
\hline Return $[2,4)$ & $\begin{array}{c}0.0249 * * * \\
(0.00181)\end{array}$ & $\begin{array}{c}-0.0341 * * * \\
(0.00276)\end{array}$ & $\begin{array}{c}0.0337 * * * \\
(0.00225)\end{array}$ & $\begin{array}{c}-0.0323^{* * *} \\
(0.00249)\end{array}$ \\
\hline Return $[4,6)$ & $\begin{array}{c}0.0344^{* * *} \\
(0.00197)\end{array}$ & $\begin{array}{c}-0.0272^{* * *} \\
(0.00318)\end{array}$ & $\begin{array}{c}0.0498^{* * *} \\
(0.00287)\end{array}$ & $\begin{array}{c}-0.0259 * * * \\
(0.00323)\end{array}$ \\
\hline Return $[6,8)$ & $\begin{array}{c}0.0378^{* * *} \\
(0.00185)\end{array}$ & $\begin{array}{c}-0.0268 * * * \\
(0.00357)\end{array}$ & $\begin{array}{c}0.0582^{* * *} \\
(0.00338)\end{array}$ & $\begin{array}{c}-0.0247^{* * *} \\
(0.00339)\end{array}$ \\
\hline Return $[8,10)$ & $\begin{array}{c}0.0388^{* * *} \\
(0.00224)\end{array}$ & $\begin{array}{c}-0.0227^{* * *} \\
(0.00357)\end{array}$ & $\begin{array}{c}0.0652^{* * *} \\
(0.00426)\end{array}$ & $\begin{array}{c}-0.0214^{* * *} \\
(0.00354)\end{array}$ \\
\hline Return $[10,12)$ & $\begin{array}{c}0.0410^{* * *} \\
(0.00241)\end{array}$ & $\begin{array}{c}-0.0235^{* * *} \\
(0.00382)\end{array}$ & $\begin{array}{c}0.0713 * * * \\
(0.00406)\end{array}$ & $\begin{array}{c}-0.0172 * * * \\
(0.00349)\end{array}$ \\
\hline Return $[12,14)$ & $\begin{array}{c}0.0371 * * * \\
(0.00236)\end{array}$ & $\begin{array}{c}-0.0238^{* * *} \\
(0.00353)\end{array}$ & $\begin{array}{c}0.0672 * * * \\
(0.00373)\end{array}$ & $\begin{array}{c}-0.0187^{* * *} \\
(0.00351)\end{array}$ \\
\hline Return $[14,16)$ & $\begin{array}{c}0.0337^{* * *} \\
(0.00273)\end{array}$ & $\begin{array}{c}-0.0223 * * * \\
(0.00337)\end{array}$ & $\begin{array}{c}0.0660 * * * \\
(0.00380)\end{array}$ & $\begin{array}{c}-0.0182^{* * *} \\
(0.00330)\end{array}$ \\
\hline Return $[16,18)$ & $\begin{array}{c}0.0332^{* * *} \\
(0.00285)\end{array}$ & $\begin{array}{c}-0.0253^{* * *} \\
(0.00323)\end{array}$ & $\begin{array}{c}0.0628 * * * \\
(0.00408)\end{array}$ & $\begin{array}{c}-0.0206 * * * \\
(0.00333)\end{array}$ \\
\hline Return $[18,20)$ & $\begin{array}{c}0.0313^{* * *} \\
(0.00284)\end{array}$ & $\begin{array}{c}-0.0252^{* * *} \\
(0.00324)\end{array}$ & $\begin{array}{c}0.0621 * * * \\
(0.00470)\end{array}$ & $\begin{array}{c}-0.0219 * * * \\
(0.00328)\end{array}$ \\
\hline Return $[20,22)$ & $\begin{array}{c}0.0319 * * * \\
(0.00274)\end{array}$ & $\begin{array}{c}-0.0283^{* * *} \\
(0.00322)\end{array}$ & $\begin{array}{c}0.0634^{* * *} \\
(0.00395)\end{array}$ & $\begin{array}{c}-0.0211^{* * *} \\
(0.00336)\end{array}$ \\
\hline Return $[22,24)$ & $\begin{array}{c}0.0290 * * * \\
(0.00274)\end{array}$ & $\begin{array}{c}-0.0282^{* * *} \\
(0.00331)\end{array}$ & $\begin{array}{c}0.0553 * * * \\
(0.00437)\end{array}$ & $\begin{array}{c}-0.0227^{* * *} \\
(0.00311)\end{array}$ \\
\hline Return $[24,26)$ & $\begin{array}{c}0.0252^{* * *} \\
(0.00292)\end{array}$ & $\begin{array}{c}-0.0277^{* * *} \\
(0.00301)\end{array}$ & $\begin{array}{c}0.0538^{* * *} \\
(0.00444)\end{array}$ & $\begin{array}{c}-0.0230 * * * \\
(0.00345)\end{array}$ \\
\hline Return $[26,28)$ & $\begin{array}{c}0.0275^{* * *} \\
(0.00312)\end{array}$ & $\begin{array}{c}-0.0300 * * * \\
(0.00303)\end{array}$ & $\begin{array}{c}0.0540 * * * \\
(0.00491)\end{array}$ & $\begin{array}{c}-0.0220 * * * \\
(0.00293)\end{array}$ \\
\hline Return $[28,30)$ & $\begin{array}{c}0.0227^{* * *} \\
(0.00313)\end{array}$ & $\begin{array}{c}-0.0288^{* * *} \\
(0.00327)\end{array}$ & $\begin{array}{c}0.0516^{* * *} \\
(0.00442)\end{array}$ & $\begin{array}{c}-0.0230 * * * \\
(0.00357)\end{array}$ \\
\hline Return [30) & $\begin{array}{c}0.0193 * * * \\
(0.00329)\end{array}$ & $\begin{array}{c}-0.0416^{* * *} \\
(0.00300)\end{array}$ & $\begin{array}{c}0.0435 * * * \\
(0.00388)\end{array}$ & $\begin{array}{c}-0.0366 * * * \\
(0.00330)\end{array}$ \\
\hline Observations & & 829 & & 462 \\
\hline R-squared & & & & \\
\hline Cluster investor-month & & & & \\
\hline Investor FE & & & & \\
\hline Month FE & & & & \\
\hline
\end{tabular}




\section{Appendix F: The impact of time on the selling pattern in boom and bust periods}

This table examines the effect time on investors' selling pattern in boom and bust markets. We report the results of various regressions for Panel A (Gains) and Panel B (Losses), i.e. Panel A contains all assets trading at a gain, while Panel B contains all assets trading at a loss. Sale, Gain, and Boom are defined as in regression (1) to (2). Quartile2, Quartile3, and Quartile4 are dummy variables that equal one if the asset belongs to the quartile respectively. Quartile 1 as base quartile is subsumed in the constant. Assets that are sold at the beginning of the boom (bust) period are part of quartile 1, whereas assets sold at the end of the boom (bust) period are part of quartile 4. Standard errors (in parentheses) are two-way clustered by investor and month. *, **, and *** indicate statistical significance at the $10 \%, 5 \%$, and $1 \%$ levels, respectively.

\begin{tabular}{|c|c|c|}
\hline Dependent Variable: Sale & $\begin{array}{c}\text { (1) } \\
\text { Pooled }\end{array}$ & $\begin{array}{c}\text { (2) } \\
\text { Pooled }\end{array}$ \\
\hline Gain & $\begin{array}{l}0.121^{* * *} \\
(0.0134)\end{array}$ & $\begin{array}{l}0.103 * * * \\
(0.0132)\end{array}$ \\
\hline Boom & $\begin{array}{c}-0.0236 * * * \\
(0.00765)\end{array}$ & $\begin{array}{l}-0.00914 \\
(0.00715)\end{array}$ \\
\hline Quartile 2 & $\begin{array}{l}-0.0156^{*} \\
(0.00876)\end{array}$ & $\begin{array}{l}-0.0109 \\
(0.00735)\end{array}$ \\
\hline Quartile 3 & $\begin{array}{c}-0.0337 * * * \\
(0.00671)\end{array}$ & $\begin{array}{r}-0.0251 * * * \\
(0.00631)\end{array}$ \\
\hline Quartile 4 & $\begin{array}{c}-0.0236 * * * \\
(0.00790)\end{array}$ & $\begin{array}{l}-0.0162^{* *} \\
(0.00722)\end{array}$ \\
\hline Gain $\times$ Boom & $\begin{array}{c}-0.0540 * * * \\
(0.0142)\end{array}$ & $\begin{array}{c}-0.0387^{* * *} \\
(0.0139)\end{array}$ \\
\hline Gain $\times$ Quartile 2 & $\begin{array}{l}-0.00331 \\
(0.0163)\end{array}$ & $\begin{array}{l}0.00168 \\
(0.0152)\end{array}$ \\
\hline Gain $\times$ Quartile 3 & $\begin{array}{l}0.00883 \\
(0.0182)\end{array}$ & $\begin{array}{c}0.0161 \\
(0.0167)\end{array}$ \\
\hline Gain $\times$ Quartile 4 & $\begin{array}{c}-0.0389 * * \\
(0.0153)\end{array}$ & $\begin{array}{l}-0.0227 \\
(0.0147)\end{array}$ \\
\hline Boom $\times$ Quartile 2 & $\begin{array}{l}0.0197^{*} \\
(0.0112)\end{array}$ & $\begin{array}{c}0.0171^{*} \\
(0.00882)\end{array}$ \\
\hline Boom $\times$ Quartile 3 & $\begin{array}{c}0.0478 * * * \\
(0.00867)\end{array}$ & $\begin{array}{r}0.0442 * * * \\
(0.00825)\end{array}$ \\
\hline Boom $\times$ Quartile 4 & $\begin{array}{c}0.0275^{* * *} \\
(0.0102)\end{array}$ & $\begin{array}{r}0.0292 * * * \\
(0.00954)\end{array}$ \\
\hline Gain $\times$ Boom*Quartile 2 & $\begin{array}{l}-0.00869 \\
(0.0177)\end{array}$ & $\begin{array}{l}-0.0102 \\
(0.0168)\end{array}$ \\
\hline Gain $\times$ Boom* Quartile 3 & $\begin{array}{l}-0.0284 \\
(0.0199)\end{array}$ & $\begin{array}{l}-0.0287 \\
(0.0185)\end{array}$ \\
\hline Gain $\times$ Boom* Quartile 4 & $\begin{array}{c}0.0159 \\
(0.0170)\end{array}$ & $\begin{array}{l}0.00922 \\
(0.0164)\end{array}$ \\
\hline Constant & $\begin{array}{l}0.171^{* * *} \\
(0.00781)\end{array}$ & \\
\hline Observations & $17,723,068$ & $17,720,100$ \\
\hline R-squared & 0.019 & 0.093 \\
\hline Cluster investor-month & YES & YES \\
\hline $\begin{array}{l}\text { Number of Assets in PF } \\
\text { Investor FE }\end{array}$ & YES & $\begin{array}{l}\text { YES } \\
\text { YES }\end{array}$ \\
\hline
\end{tabular}




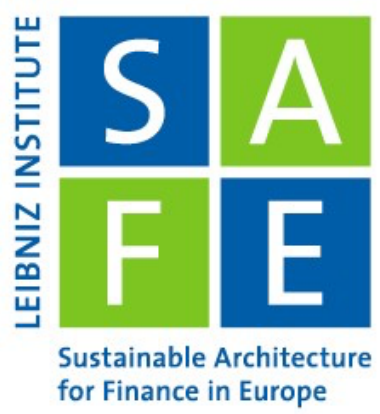

\section{Recent Issues}

No. 304 Monica Billio, Andrew W. Lo, Loriana Pelizzon, Mila Getmansky Sherman, Abalfazl Zareei

No. 303 Ankit Kalda, Benjamin Loos, Alessandro Previtero, Andreas Hackethal

No. 302 Tim A. Kroencke, Maik Schmeling, Andreas Schrimpf

No. 301 Di Bu, Tobin Hanspal, Yin Liao, Yong Liu

No. 300 Dennis Gram, Pantelis Karapanagiotis, Jan Krzyzanowski, Marius Liebald, Uwe Walz

No. 299 Ferdinand A. von Siemen

No. 298

Calebe de Roure, Emanuel Moench, Loriana Pelizzon, Michael Schneider

No. 297 Dimitrios Kostopoulos, Steffen Meyer, Charline Uhr

No. 296 Reint Gropp, Thomas Mosk, Steven Ongena, Ines Simac, Carlo Wix

No. 295 Besart Avdiu, Alfons J. Weichenrieder

No. 294 Christian Alemán, Christopher Busch, Alexander Ludwig, Raül Santaeulàlia-Llopis

No. 293 Christoph Hambel, Holger Kraft, André Meyer-Wehmann

No. 292 Andrea Modena
Global Realignment in Financial Market Dynamics: Evidence from ETF Networks

Smart (Phone) Investing?

A Within Investor-Time Analysis of New Technologies and Trading Behavior

The FOMC Risk Shift

Risk Taking, Preferences, and Beliefs:

Evidence from Wuhan

An Extensible Model for Historical Financial Data with an Application to German Company and Stock Market Data

Motivated Beliefs and the Elderly's Compliance with COVID-19 Measures

OTC Discount

Ambiguity and Investor Behavior

Supranational Rules, National Discretion: Increasing Versus Inflating Regulatory Bank Capital?

Financing Costs and the Efficiency of PublicPrivate Partnerships

Evaluating the Effectiveness of Policies Against a Pandemic

When Should Retirees Tap Their Home Equity?

Recapitalization, Bailout, and Long-run Welfare in a Dynamic Model of Banking 